\title{
EDTA-Functionalized Activated Carbon for the Adsorption of Rare Earths from Aqueous Solutions
}

\author{
Cadiam Mohan Babu, Koen Binnemans, and Joris Roosen
}

Ind. Eng. Chem. Res., Just Accepted Manuscript • DOI: 10.1021/acs.iecr.7b04274 • Publication Date (Web): 10 Jan 2018

Downloaded from http://pubs.acs.org on January 11, 2018

\section{Just Accepted}

"Just Accepted" manuscripts have been peer-reviewed and accepted for publication. They are posted online prior to technical editing, formatting for publication and author proofing. The American Chemical Society provides "Just Accepted" as a free service to the research community to expedite the dissemination of scientific material as soon as possible after acceptance. "Just Accepted" manuscripts appear in full in PDF format accompanied by an HTML abstract. "Just Accepted" manuscripts have been fully peer reviewed, but should not be considered the official version of record. They are accessible to all readers and citable by the Digital Object Identifier (DOI®). "Just Accepted" is an optional service offered to authors. Therefore, the "Just Accepted" Web site may not include all articles that will be published in the journal. After a manuscript is technically edited and formatted, it will be removed from the "Just Accepted" Web site and published as an ASAP article. Note that technical editing may introduce minor changes to the manuscript text and/or graphics which could affect content, and all legal disclaimers and ethical guidelines that apply to the journal pertain. ACS cannot be held responsible for errors or consequences arising from the use of information contained in these "Just Accepted" manuscripts.

B.C. Mohan, K. Binnemans, J. Roosen

Industrial \& Engineering Chemistry Research 57, 1487-1497 (2018).

DOI: $10.1021 / a c s . i e c r .7 b 04274$ 


\title{
EDTA-Functionalized Activated Carbon for the
}

\section{Adsorption of Rare Earths from Aqueous Solutions}

\author{
Cadiam Mohan Babu ${ }^{\mathrm{a}, \mathrm{b}}$, Koen Binnemans ${ }^{\mathrm{a}}$ and Joris Roosen ${ }^{\mathrm{a}, \mathrm{b} *}$ \\ ${ }^{a}$ KU Leuven, Department of Chemistry, Celestijnenlaan 200F, P.O. Box 2404, B-3001 \\ Heverlee, Belgium. \\ b SIM vzw, Technologiepark 935, B-9052 Zwijnaarde, Belgium. \\ * Corresponding author. Email: joris.roosen@kuleuven.be. Phone: +32 16328204.
}




\begin{abstract}
A novel and low-cost EDTA-functionalized activated carbon (EDTA-AC) was synthesized by anchoring $N$-[(3-trimethoxysilyl)propyl]ethylenediamine triacetic acid (TMS-EDTA) to oxidized activated carbon (AC). Material characterization was done by FTIR and Raman spectroscopy, TGA, $\mathrm{N}_{2}$ physisorption, SEM and the Boehm titration method, the latter being used to determine the amount and type of oxygen functional groups present in carbon samples. EDTA-AC was tested for the adsorption and separation of rare-earth ions from aqueous solutions, in order to evaluate the feasibility of using this material for the recovery of rare earths from industrial residues and electronic waste, like batteries, magnets and lamp phosphors. The maximum adsorption capacity of EDTA-AC was derived for $\mathrm{Nd}(\mathrm{III})$ by constructing an adsorption isotherm and fitting the data to the Langmuir adsorption model. A kinetic and thermodynamic study were performed by varying the contact time and the temperature and plotting the corresponding adsorption data to the pseudo-second-order kinetic model and the Van ' $t$ Hoff equation, respectively. The affinity of EDTA-AC for each of the lanthanide ions was determined and from binary mixtures of $\mathrm{La} / \mathrm{Ni}, \mathrm{Sm} / \mathrm{Co}$ and $\mathrm{Eu} / \mathrm{Y}$, the highest selectivity was observed for the rare earths. The adsorbed metal ions could be recovered and the adsorbent regenerated by treatment with a dilute solution of $\mathrm{HCl}$, thus showing the (large-scale) potential of EDTA-functionalized AC for the recovery of rare earths from aqueous waste streams.
\end{abstract}

Keywords: Activated carbon, EDTA, Rare-earth elements, Adsorption, Recovery 


\section{INTRODUCTION}

Since recent decades, the discharge of waste water containing rare-earth elements (REEs) into the environment has gotten more attention. Various industrial activities are involved, such as the production of electronic devices, the application of catalysts and chemical sensors, nuclear power plants, chemical engineering and mining. ${ }^{1,2}$ Contamination of waste water with rare earths creates a serious threat to environment and human health because of their toxicity, non-biodegradability and accumulation in living organisms. ${ }^{3,4}$ Moreover, since rare earths are invaluable for a wide range of hightechnological applications, their recovery may allow turning disposal costs into revenues. Many techniques have been attempted to recover REEs from waste water, including liquid-liquid extraction, ion exchange, chemical precipitation, electrolysis and adsorption. ${ }^{5,6}$ Among these, adsorption is generally considered the preferred technology, due to its combined simplicity, effectiveness and low cost. ${ }^{7}$

A large number of organic and inorganic adsorbents have been employed for the adsorption of REEs, such as alumina,${ }^{8}$ crown ethers, ${ }^{9}$ ionic-liquid impregnated resins, ${ }^{10}$ chitosan, ${ }^{11}$ silica ${ }^{12}$ and carbon based nanomaterials (graphene oxide and carbon nanotubes). ${ }^{13,14}$ Among these, activated carbons (ACs) are widely being explored as adsorbents and catalysts in the emerging field of environmental and energy applications because of their well-developed porous structure and tunable surface chemistry. ${ }^{15,16}$ The interest for using activated carbon (AC) in adsorption processes may be explained by the unlimited availability of natural carbon sources (such as agricultural waste), ${ }^{17,18}$ its environmentally friendly nature, its low cost and its ability to be used in a wide range of 
process temperatures and pressures. ${ }^{19,20}$ The adsorbing property of AC can be enhanced by proper oxidation methods, so as to create oxygen containing functional groups, such as $-\mathrm{OH}, \mathrm{C}-\mathrm{O}, \mathrm{C}=\mathrm{O},-\mathrm{COOH}$ and $-\mathrm{COOR}$, at the most reactive centers of the carbon matrix. $^{21}$

Starvin and Rao have reported that the use of native AC is not suitable to adsorb trace levels of (heavy) metal ions. ${ }^{22}$ To improve the adsorption performance, the nature and concentration of the functional groups, AC can be modified by various surface treatments such as functionalization with other products. ${ }^{23}$ In addition to the formation of nonselective oxygen surface groups, the adsorption capacity and selectivity of AC materials may be further improved by immobilizing chelating agents. Many organic functional moieties have been used for the surface functionalization of several support materials. ${ }^{24-28}$ Ethylenediamine tetraacetic acid (EDTA), a polyaminocarboxylic acid, has been used in many applications, including dyeing auxiliaries, stabilizers, and coordination compounds. ${ }^{29}$ As well in the context of waste water treatment, many literature reports have discussed the use of EDTA as a prompting agent for the adsorption of metals from aqueous solutions through a complexation mechanism. ${ }^{30-36}$ In our group, EDTA has been covalently attached to magnetic iron nanoparticles, chitosan and chitosan-silica. ${ }^{37,38} \mathrm{We}$ found that immobilization of EDTA results in materials with a good resistance against acidic environment and with a high selectivity for and amongst rare-earth ions by the formation of stable coordination complexes. Consequently, mutual separation of the adsorbed REEs is quite straightforward, by simply adjusting the $\mathrm{pH}$ of the aqueous solution. Hence, EDTA may be a highly preferred ligand to decorate the surface of AC. 
However, to the best of our knowledge, the use of EDTA-functionalized AC (for adsorption of REEs or another application) has not been documented before. The purpose of this study is to investigate the surface functionalization of AC using $\mathrm{N}$ [(3-trimethoxysilyl)propyl]ethylenediamine triacetic acid (TMS-EDTA) and to examine the adsorption of rare earths from aqueous solution with these EDTA-functionalized AC materials. By investigating the selectivity of EDTA-AC for REEs, we can hopefully demonstrate that this material is suited for their selective recovery from waste water. 


\section{EXPERIMENTAL SECTION}

\subsection{Reagents and materials}

Powdered activated carbon, Norit ${ }^{\circledR}$ SX1G from Cabot Corporation (USA), was used as the AC source in this study. $N$-[(3-trimethoxysilyl)propyl]ethylenediamine triacetic acid trisodiumsalt (TMS-EDTA, $45 \mathrm{wt} \%$ ) was purchased from ABCR chemicals, $\mathrm{Ce}\left(\mathrm{NO}_{3}\right)_{3} \cdot 6 \mathrm{H}_{2} \mathrm{O}(99.9 \%)$ and $\mathrm{Y}\left(\mathrm{NO}_{3}\right)_{3} \cdot 6 \mathrm{H}_{2} \mathrm{O}(99.8 \%)$ from Sigma-Aldrich, $\mathrm{Co}\left(\mathrm{NO}_{3}\right)_{2} \cdot 6 \mathrm{H}_{2} \mathrm{O}(99.9 \%), \mathrm{Ni}\left(\mathrm{NO}_{3}\right)_{2} \cdot 6 \mathrm{H}_{2} \mathrm{O}(99.9 \%), \mathrm{Er}\left(\mathrm{NO}_{3}\right)_{3} \cdot 5 \mathrm{H}_{2} \mathrm{O}(99.9 \%)$, $\mathrm{Gd}\left(\mathrm{NO}_{3}\right)_{3} \cdot 6 \mathrm{H}_{2} \mathrm{O}(99.9 \%)$ and $\mathrm{Sm}\left(\mathrm{NO}_{3}\right)_{3} \cdot 6 \mathrm{H}_{2} \mathrm{O}(99.9 \%)$ were purchased from Acros Chemicals. $\operatorname{Pr}\left(\mathrm{NO}_{3}\right)_{3} \cdot 6 \mathrm{H}_{2} \mathrm{O}(99.9 \%)$ and $\mathrm{La}\left(\mathrm{NO}_{3}\right)_{3} \cdot 6 \mathrm{H}_{2} \mathrm{O}(99.9 \%)$ were purchased from Chempur. $\mathrm{Tb}\left(\mathrm{NO}_{3}\right)_{3} \cdot 5 \mathrm{H}_{2} \mathrm{O}(99.9 \%), \mathrm{Nd}\left(\mathrm{NO}_{3}\right)_{3} \cdot 6 \mathrm{H}_{2} \mathrm{O}(99.9 \%), \mathrm{Ho}\left(\mathrm{NO}_{3}\right)_{3} \cdot 5 \mathrm{H}_{2} \mathrm{O}(99.9 \%)$, $\mathrm{Eu}\left(\mathrm{NO}_{3}\right)_{3} \cdot 5 \mathrm{H}_{2} \mathrm{O}(99.9 \%), \mathrm{Dy}\left(\mathrm{NO}_{3}\right)_{3} \cdot 5 \mathrm{H}_{2} \mathrm{O}(99.9 \%), \mathrm{Yb}\left(\mathrm{NO}_{3}\right)_{3} \cdot 5 \mathrm{H}_{2} \mathrm{O}(99.9 \%)$, methanol, ethanol and glacial acetic acid (99.7 \%) were purchased from Alfa Aesar. All chemicals were of analytical grade and used without further purification. All solutions were prepared using $18.2 \mathrm{M} \Omega \cdot \mathrm{cm}$ Milli- $\mathrm{Q}^{\circledR}$ water.

\subsection{Synthesis of EDTA-functionalized activated carbon}

EDTA-functionalized AC was synthesized by reacting oxidized activated carbon with TMS-EDTA. Briefly, to $5 \mathrm{~g}$ of AC in a $250 \mathrm{~mL}$ three-neck flask, $50 \mathrm{~mL}$ of concentrated $\mathrm{HNO}_{3}(15 \mathrm{M})$ was slowly added after which the mixture refluxed at $85^{\circ} \mathrm{C}$ for $6 \mathrm{~h}$. Note that the combination of fine AC powder (with a high specific surface area) and strong acids or oxidizing agents can be explosive. Then, the residue was filtered and washed several times with deionized water until the $\mathrm{pH}$ was neutral and dried under 
vacuum at $50{ }^{\circ} \mathrm{C}$ to obtain oxidized activated carbon. The optimized functionalization of TMS-EDTA over oxidized AC was performed in an isopropanol/water (85:15) solvent mixture. ${ }^{40}$ Briefly, $1 \mathrm{~g}$ of oxidized $\mathrm{AC}$ was added to a $250 \mathrm{~mL}$ round-bottom flask containing $200 \mathrm{~mL}$ of isopropanol/water ( $85: 15$ volume ratio) and the $\mathrm{pH}$ was adjusted to a value of 4 to 5 with $\mathrm{HCl}$. The mixture was ultrasonicated for $2 \mathrm{~h}$ to get a uniform dispersion. Then, the beaker was set in stirring mode and $5 \mathrm{~mL}$ of TMS-EDTA was slowly added dropwise to the solution. $1 \mathrm{~mL}$ of acetic acid was added to the solution to increase the amount of condensation reactions between the $-\mathrm{OH}$ groups of activated carbon and the hydrolyzed silanol groups in TMS-EDTA. The reaction mixture was stirred for $24 \mathrm{~h}$ at room temperature. After functionalization, the particles were filtrated and washed with water and acetone. Finally, the EDTA-functionalized AC particles (EDTA-AC) were dried in vacuum at $50^{\circ} \mathrm{C}$. The synthesis procedure of EDTA-AC is depicted in Scheme 1.

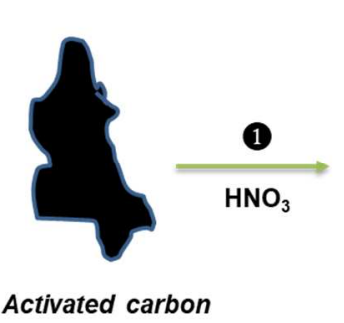

Activated carbon

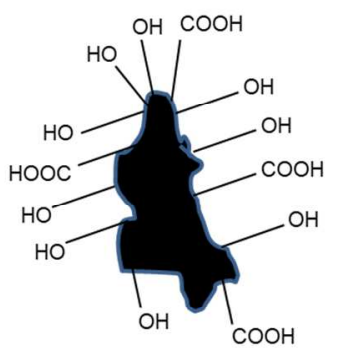

Oxidized activated carbon

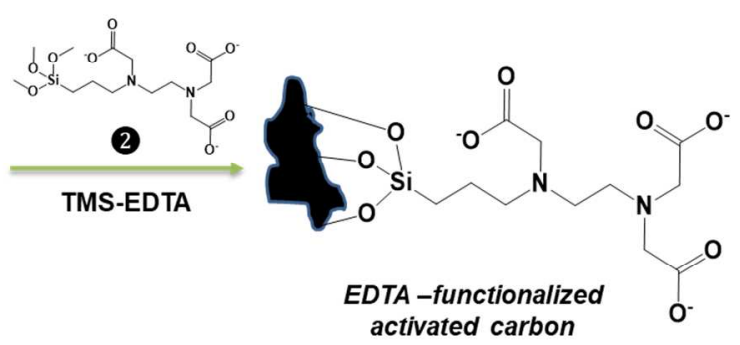

Scheme 1. Schematic diagram for the synthesis of EDTA-functionalized AC.

\subsection{Characterization}

The morphology of the synthesized materials was examined by scanning electron microscopy (SEM) using a Philips XL30 model, preceded by platinum sample coating. Fourier Transform InfraRed (FTIR) spectra were measured between 4000 and $400 \mathrm{~cm}^{-1}$ 
on a Bruker Vertex 70 spectrometer with a Platinum ATR module. The Raman spectra were recorded from 1000 to $1800 \mathrm{~cm}^{-1}$ on a Bruker RAMII spectrometer using a $515.5 \mathrm{~nm}$ He-Ne laser source. Thermal stability of the materials was analyzed by means of a TA Instruments Q600 thermogravimetric analyzer (TGA), measuring under nitrogen atmosphere from room temperature to $800{ }^{\circ} \mathrm{C}$ at a heating rate of $5{ }^{\circ} \mathrm{C} \min ^{-1}$. CHN elemental analyses were performed with a Flash 2000 Elemental analyzer of Thermo Scientific Interscience. The oxygen percentage was derived in the assumption that only $\mathrm{C}$, $\mathrm{H}, \mathrm{N}$ and $\mathrm{O}$ atoms are present in the AC samples. Nitrogen adsorption-desorption isotherms were recorded at $77 \mathrm{~K}$ on a NOVA $2020 \mathrm{E}$ volumetric adsorption analyzer to evaluate area-volume data of AC. Prior to the measurement, the AC materials were degassed for $24 \mathrm{~h}$ at $150{ }^{\circ} \mathrm{C}$ under vacuum. The specific surface area of the samples was calculated by use of the Brunauer- Emmett-Teller (BET) method, and the pore size distribution and pore volume were calculated with the Barrett-Joyner-Halenda (BJH) method. A Mettler-Toledo $\mathrm{pH}$ meter was used to measure the $\mathrm{pH}$ of the solutions. Particle size distributions were measured by laser particle size analysis on a Malvern Mastersizer 3000. The aqueous rare-earth concentrations were measured by Total reflection X-Ray Fluorescence (TXRF) analysis. A benchtop Bruker S2 PICOFOX spectrometer equipped with a molybdenum X-ray source was used. Samples were prepared for analysis in Eppendorf microtubes, where the sample solution was mixed with an internal standard solution (1000 ppm gallium dissolved in $2-3 \% \mathrm{HNO}_{3}$ ). Gallium was selected as the internal standard because it has a high sensitivity and does not interfere with the lanthanide signals. Finally, a $5 \mu \mathrm{L}$ drop of the mixed solution was put on a quartz plate, after treating it with a Serva ${ }^{\circledR}$ silicone/isopropanol solution, and dried for $30 \mathrm{~min}$ at $60{ }^{\circ} \mathrm{C}$ 
prior to analysis. Each analytical sample was prepared in duplicate and measured for $300 \mathrm{~s}$.

The Boehm titration method was used to evaluate the oxygen surface functional groups. ${ }^{39}$ Carbon $(250 \mathrm{mg})$ was added separately to $50 \mathrm{~mL}$ of a $0.05 \mathrm{M} \mathrm{NaHCO}_{3}, \mathrm{Na}_{2} \mathrm{CO}_{3}$ and $\mathrm{NaOH}$ solution, respectively. The samples were agitated for $24 \mathrm{~h}$ and the $\mathrm{AC}$ particles were removed by filtration. Then, $10 \mathrm{~mL}$ aliquots of the reaction base solutions, i.e. $\mathrm{NaHCO}_{3}, \mathrm{Na}_{2} \mathrm{CO}_{3}$ and $\mathrm{NaOH}$, were titrated with $0.05 \mathrm{M} \mathrm{HCl}$. Freshly prepared solutions were used and continuously purged with $\mathrm{N}_{2}$ gas (before and during titration) to limit $\mathrm{CO}_{2}$ permeation. Blank samples without carbon were also run with each reaction base.

\subsection{Adsorption of EDTA-AC}

In a glass $20 \mathrm{~mL}$ vial, $20 \mathrm{mg}$ of functionalized particles were added to $10 \mathrm{~mL}$ of a rare-earth solution. Unless stated otherwise, a $1 \mathrm{mM} \mathrm{Nd(III)} \mathrm{solution} \mathrm{was} \mathrm{used,} \mathrm{readily}$ diluted from an acidified $10 \mathrm{mM}$ stock solution that was prepared from the corresponding nitrate salt. The $\mathrm{pH}$ of the solution was adjusted to a value of 5.0 by dropwise addition of a $0.1 \mathrm{M} \mathrm{NaOH}$ solution. The adsorption experiments were maintained for $4 \mathrm{~h}$ by shaking the solutions at $250 \mathrm{rpm}$ and $20^{\circ} \mathrm{C}$ in a mechanical shaker (IKA KS 130 basic with universal attachment).

After adsorption, the solid AC particles were separated from the liquid by centrifugation at $5000 \mathrm{rpm}$ for $20 \mathrm{~min}$, using an Eppendorf 5804 centrifuge. In the desorption and reusability experiments, the separated nanoparticles were washed twice 
with acetone and re-dispersed in water. Then, the $\mathrm{pH}$ of the solution was lowered using 1 $\mathrm{M} \mathrm{HCl}$ to ensure stripping of the loaded metal ions from EDTA-AC. Aqueous metal concentrations were analyzed by TXRF. The equilibrium adsorption amount $\left(q_{e}\right)$ was then calculated by Equation 1:

$$
q_{e}=\frac{V\left(C_{0}-C_{e}\right)}{M}
$$

where $C_{0}$ and $C_{e}$ are the initial and equilibrium concentration $\left(\mathrm{mg} \mathrm{L}^{-1}\right)$ of the metal ion in solution, $V$ the aqueous volume (L) and $M$ the mass of the adsorbent (g).

In the reusability experiment, the regenerated EDTA-AC (40 mg) was used for multiple cycles. The regeneration efficiency was calculated by Equation 2:

Regeneration efficiency in cycle $x(\%)=\left(\frac{q_{e} \text { in cycle } x}{q_{e} \text { in cycle } 1}\right) \times 100$

where $q_{e}$ is the equilibrium adsorption capacity. 


\section{RESULTS AND DISCUSSION}

\subsection{Boehm titration}

The Boehm titration method was used to identify and quantify the oxygen containing functional groups present on the AC surface. These groups play a vital role in the modification and adsorption performance of the adsorbent material. In the oxidation process, nitric acid was used to produce different oxygen containing groups, such as phenolic, lactonic and carboxylic groups (Table 1). All types of functional groups increased as a function of the nitric acid concentration, in the order phenolic $>$ carboxylic $>$ lactonic. This may be explained by the formation or breakage of strong $\mathrm{C}-\mathrm{C}$ and $\mathrm{C}-\mathrm{O}$ bonds in AC. For the subsequent functionalization step, especially the amount of $-\mathrm{OH}$ (phenolic) groups was targeted, being 117, 252 and $981 \mu \mathrm{mol} \mathrm{g}{ }^{-1}$ for nitric acid concentrations of 5, 10 and $15 \mathrm{M}$, respectively. Since the highest number of phenolic groups was incorporated through oxidation with $15 \mathrm{M}$ nitric acid, this oxidation treatment was used for the preparation of particles for further functionalization with TMS-EDTA.

\section{Table 1. Comparison of surface oxygen groups originating from AC oxidation by various concentrations of nitric acid}

\begin{tabular}{lllll} 
& Total & Phenolic & Lactonic & Carboxylic \\
& $\left(\mu \mathrm{mol} \mathrm{g}^{-1}\right)$ & $\left(\mu \mathrm{mol} \mathrm{g}^{-1}\right)$ & $\left(\mu \mathrm{mol} \mathrm{g}^{-1}\right)$ & $\left(\mu \mathrm{mol} \mathrm{g}^{-1}\right)$ \\
\hline Norit AC & 460 & 45 & 135 & 280 \\
Oxidized AC & 730 & 117 & 153 & 460 \\
\hline
\end{tabular}




\begin{tabular}{|c|c|c|c|c|}
\hline$\left(\mathrm{HNO}_{3}, 5 \mathrm{M}\right)$ & & & & \\
\hline $\begin{array}{l}\text { Oxidized AC } \\
\left(\mathrm{HNO}_{3}, 10 \mathrm{M}\right)\end{array}$ & 964 & 252 & 162 & 550 \\
\hline $\begin{array}{l}\text { Oxidized AC } \\
\left(\mathrm{HNO}_{3}, 15 \mathrm{M}\right)\end{array}$ & 2314 & 981 & 171 & 1162 \\
\hline
\end{tabular}

\subsection{FTIR and Raman spectroscopy}

FTIR measurements were performed to determine the surface functional groups present in oxidized and functionalized AC using various reaction conditions. IR spectra showing the oxidation efficiency upon oxidation with $\mathrm{HNO}_{3}$ of different concentrations can be found in Figure S1. The results show the presence of absorption peaks around $3600-3300,1731,1582$, and $1300-1100 \mathrm{~cm}^{-1}$ due to the stretching vibrations of $-\mathrm{OH}$, $\mathrm{C}=\mathrm{O}, \mathrm{C}-\mathrm{C} / \mathrm{C}=\mathrm{C}$ and $\mathrm{C}-\mathrm{O}$ groups, respectively. ${ }^{41}$ When using $15 \mathrm{M} \mathrm{HNO}_{3}$, an intense peak appears at $3400 \mathrm{~cm}^{-1}$, corresponding to $-\mathrm{OH}$ vibrations. This observation was in good agreement with the results of the Boehm titration. A large abundance of $-\mathrm{OH}$ groups is required to facilitate the subsequent functionalization reactions with TMSEDTA. Hence, we decided to use $\mathrm{AC}$ oxidized by $15 \mathrm{M} \mathrm{HNO}_{3}$ for further functionalization.

Also, the functionalization of AC with TMS-EDTA was followed by FTIR. In Figure $\mathbf{S 2}$ it can be found that a methanol-water volume ratio of 85:15 showed optimal functionalization of TMS-EDTA, especially from the peaks at 1350 and $1600 \mathrm{~cm}^{-1}$, which can be attributed to, respectively, symmetrical and asymmetrical stretching modes of 
carboxylate groups present in the EDTA ligand. The intense peak around $1100 \mathrm{~cm}^{-1}$ arises from the stretching vibration of Si-O bonds. A lower water content (90:10 methanolwater) resulted in poor silanization. On the other hand, a higher water content resulted in the rapid formation of pure silica particles, separate from AC particles, which was neither intended.

As part of the optimization study, functionalization of AC with EDTA has been investigated in both a methanol/water and an isopropanol/water solvent mixture. The FTIR spectra of both materials, shown in Figure 1, illustrate that the isopropanol system resulted in a more intense peak at $1340 \mathrm{~cm}^{-1}$ (corresponding to the presence of $\mathrm{C}=\mathrm{O}$ in carboxylic acid) compared to the methanol system. This indicated that isopropanol served as a better solvent for the silane sol-gel reactions, which might be attributed to the equilibrium of the hydrolysis reactions during which methanol is formed by conversion of the methoxy groups on TMS-EDTA to hydroxyl groups, yielding functionalized silanol entities ready for subsequent condensation reactions (Equation 3):

$$
\equiv \mathrm{Si}-\mathrm{OCH}_{3}+\mathrm{H}_{2} \mathrm{O} \rightleftharpoons \mathrm{Si}-\mathrm{OH}+\mathrm{CH}_{3} \mathrm{OH}
$$




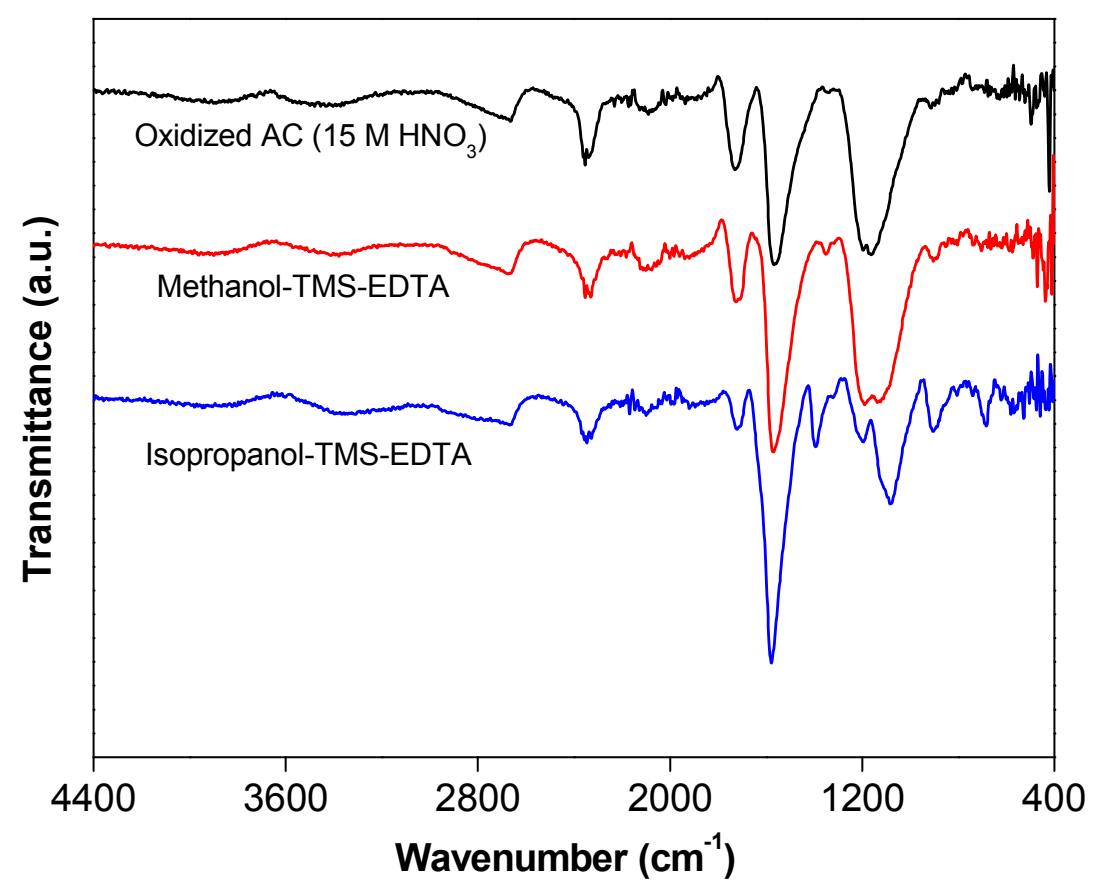

Figure 1. Comparison of FTIR spectra of EDTA-AC functionalized in methanol/water and isopropanol/water solvent mixtures with the original oxidized AC.

Based upon the sol-gel nature of the functionalization procedure, it was tried in another experiment to add different volumes of tetraethyl orthosilicate (TEOS) as a silica precursor to the reaction mixture, in order to aid the incorporation of TMS-EDTA in the functionalized AC material. The spectra in Figure $\mathbf{S 3}$ show major peaks at $1050 \mathrm{~cm}^{-1}$ and $1380 \mathrm{~cm}^{-1}$ for silica and $\mathrm{C}=\mathrm{O}$ in carboxylic acid, respectively. It was clear that the absolute amount of silica incorporation increased significantly by adding TEOS. However, CHN analysis elucidated that the relative amount of EDTA groups, or the functionalization degree, did not significantly increase in the presence of TEOS (vide 
infra). Consequently, isopropanol/water in a 85/15 volume ratio, without addition of any other silica precursor, was selected as the optimal reaction mixture for the functionalization of oxidized AC by TMS-EDTA.

Raman spectra of AC, oxidized AC and EDTA-AC are shown in Figure 2. All three exhibited two broad bands, around 1330 and $1590 \mathrm{~cm}^{-1}$, corresponding to D and G bands, respectively. The $\mathrm{D}$ band represents the structural $\mathrm{sp}^{3}$ defects with disorder induced scattering generated upon the loss of the hexagonal symmetry in the carbon structure. ${ }^{42}$ The $\mathrm{G}$ band represents the first-order scattering of the $\mathrm{E}_{2 \mathrm{~g}}$ mode for ordered $\mathrm{sp}^{2}$ carbon (graphite). The intensity ratio $\left(\mathrm{I}_{\mathrm{D}} / \mathrm{I}_{\mathrm{G}}\right)$ at the peak position can be used to measure the disorder and defects in a carbon material and is listed for AC, oxidized AC and EDTA-AC in Table S1. The intensity ratios of AC (1.31) and oxidized AC (1.33) were comparable, indicating that even after the oxidation step, a loss of symmetry did not occur in AC. In EDTA-AC an increased intensity ratio (1.48) was observed, probably due to the decoration of the AC surface with EDTA-functionalized silica molecules. 


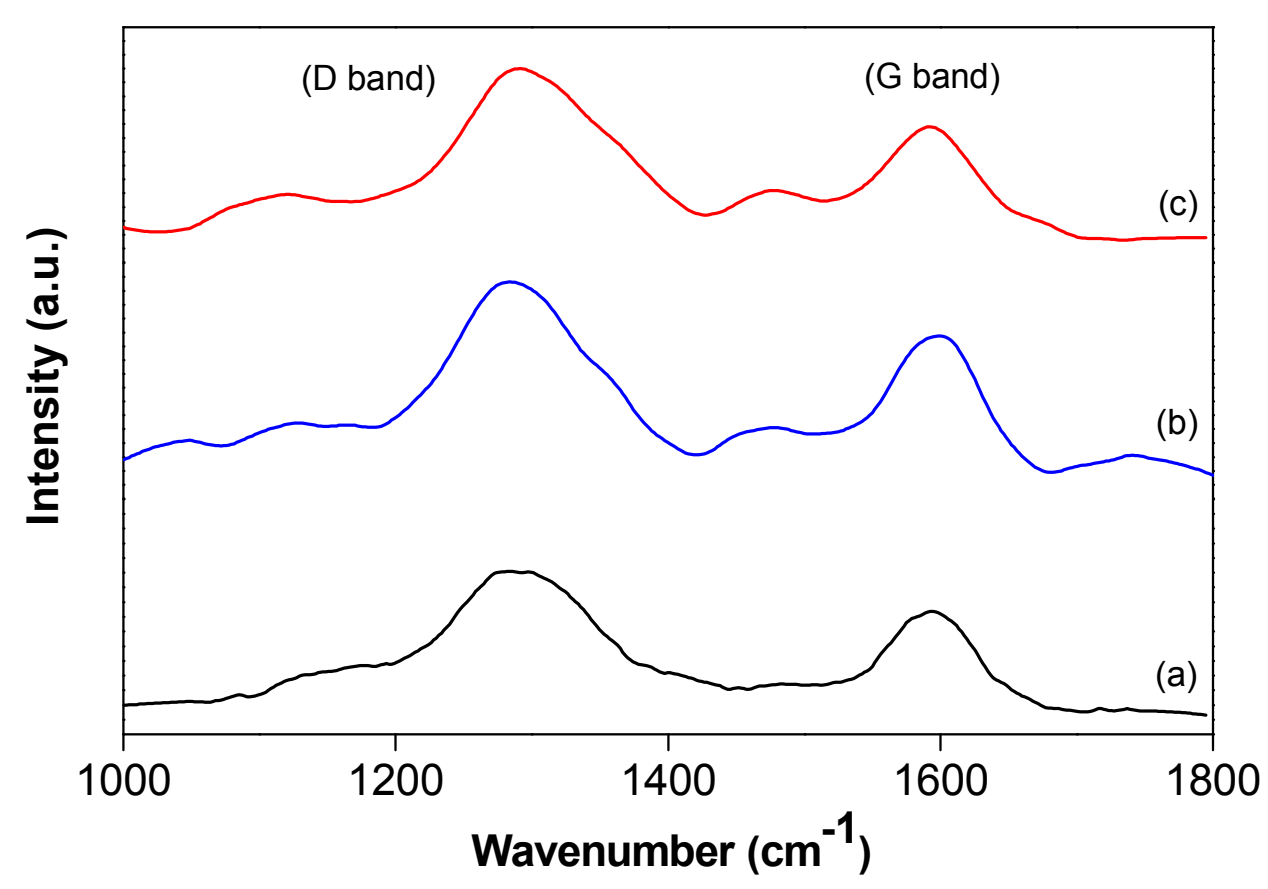

Figure 2. Raman spectra of AC (a), oxidized AC (b) and EDTA-AC (c).

\subsection{SEM and particle size analysis}

SEM images of AC, oxidized AC and EDTA-AC are shown in Figure 3. These images reveal particles of varying size and no distinct morphology. One can see that the morphology of the original AC is visually not affected by the nitric acid oxidation treatment. The EDTA-functionalized materials showed some aggregation and coating of lighter particles over the carbon particles. Evidently, these originate from the immobilization of the EDTA organic ligand on the AC support through silica linkers, as originating from TMS-EDTA. The particle size distribution of the AC samples is shown in Figure 4. In the original Norit ${ }^{\circledR} \mathrm{SX} 1 \mathrm{G}, 90 \%$ of the particles were smaller than $5.13 \mu \mathrm{m}$. Whereas the particle size did not change much after oxidation, the EDTA-functionalized 
AC showed a considerable increase in particle size, due to the immobilization of EDTAgroups on the AC particles. In the EDTA-functionalized AC only $10 \%$ of the particles were smaller than $5.84 \mu \mathrm{m}$, up to a value of $18.50 \mu \mathrm{m}$ for the $90 \%$ smallest particles (Table S2). 


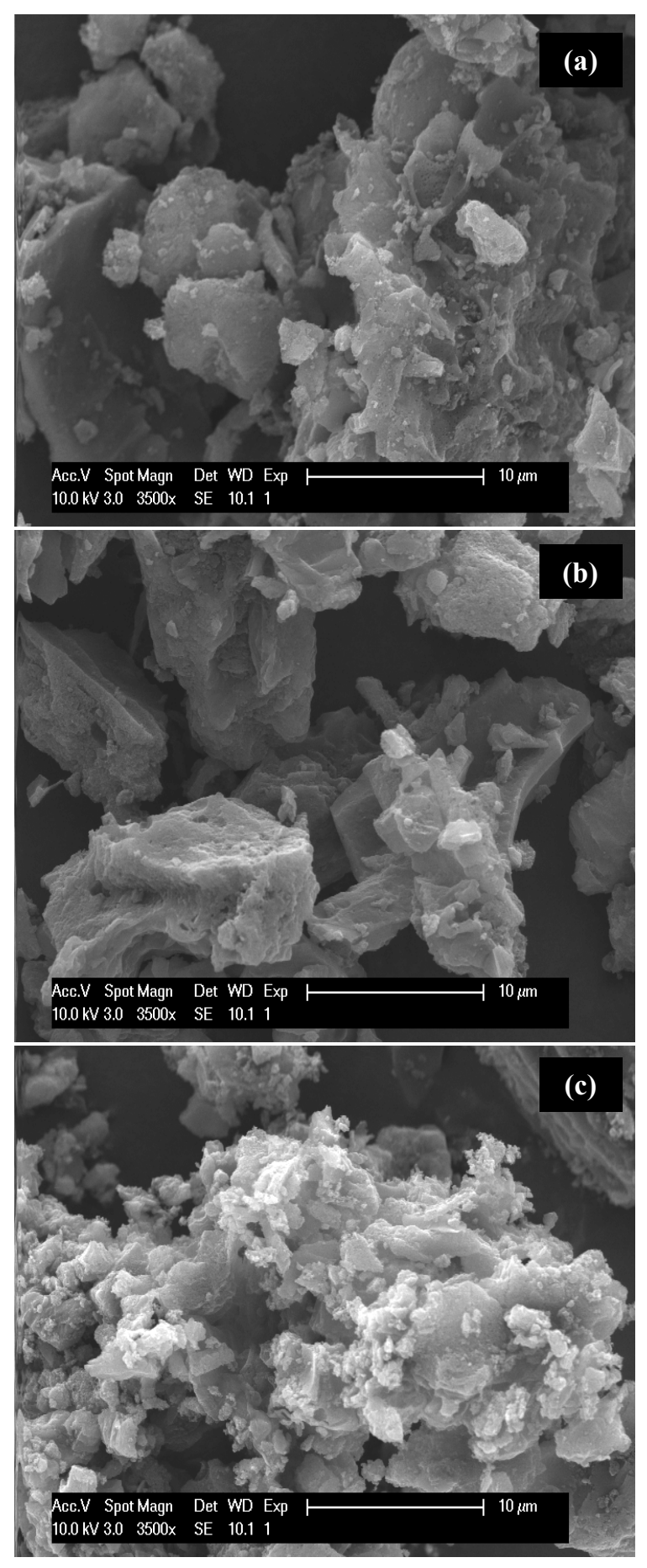

Figure 3. SEM images of AC (a), oxidized AC (b) and EDTA-AC (c). 


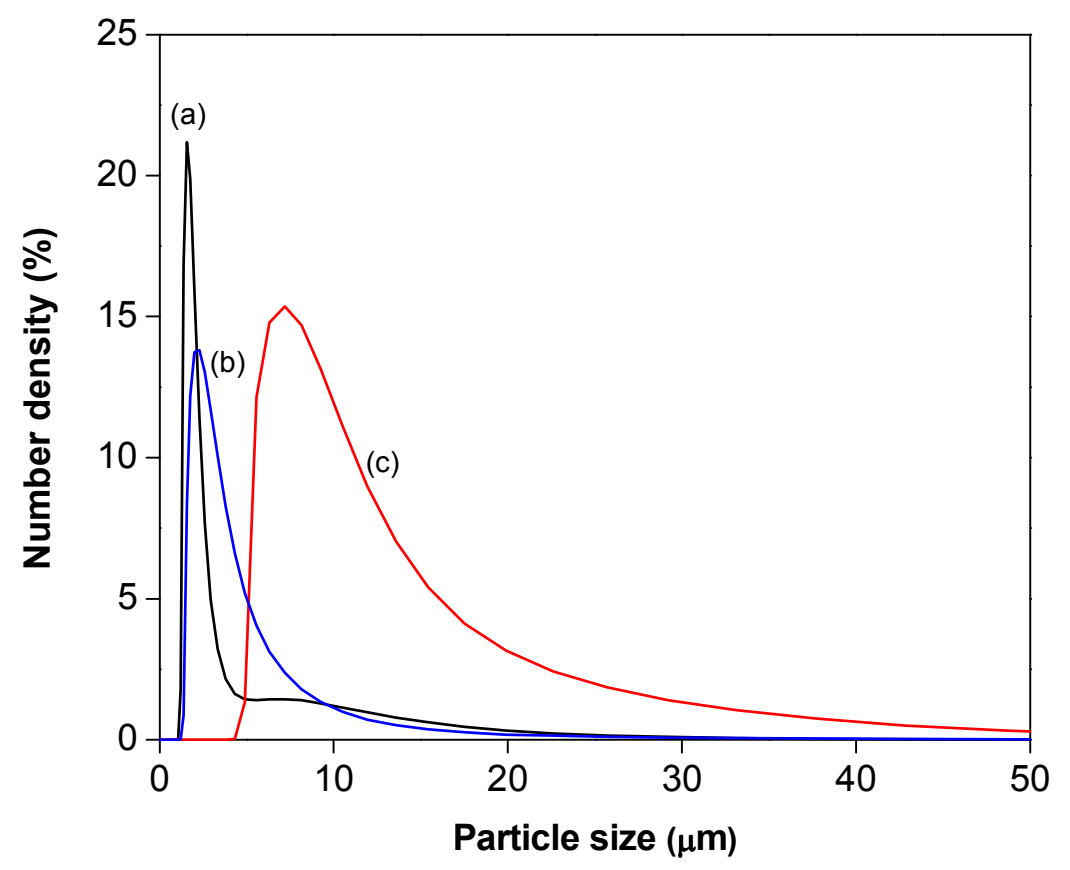

Figure 4. Particle size distribution of AC (a), oxidized AC (b) and EDTA-AC (c).

\section{4 $\mathrm{N}_{2}$ adsorption-desorption isotherms}

Textural properties of AC materials were thoroughly examined by $\mathrm{N}_{2}$ physisorption measurements. The obtained data, visualized in Figure 5, show type I isotherms with H4-hysteresis loops for all three materials, indicating a microporous nature with slit-shaped pores. ${ }^{43}$ The calculated parameters for AC, oxidized AC and EDTA-functionalized AC are presented in Table 2. The AC powder had a high surface area $\left(711 \mathrm{~m}^{2} \mathrm{~g}^{-1}\right)$. It was remarkable to observe that the harsh chemical treatment with concentrated nitric acid did not destroy the (porous) structure of the oxidized material, albeit the BET results thus confirm what was already observed from the SEM images. Functionalization with TMS-EDTA resulted in a small decrease in the surface area compared to the oxidized sample, from 761 to $741 \mathrm{~m}^{2} \mathrm{~g}^{-1}$. This may be due to some 
blocking of the microporous carbon structure by silica and organic groups present in TMS-EDTA, thus reducing the degree of crenation. From this study, we can understand that even at drastic conditions, the textural properties of the $\mathrm{AC}$ materials did not change significantly, demonstrating the high chemical stability of the used Norit ${ }^{\circledR} \mathrm{AC}$ source.

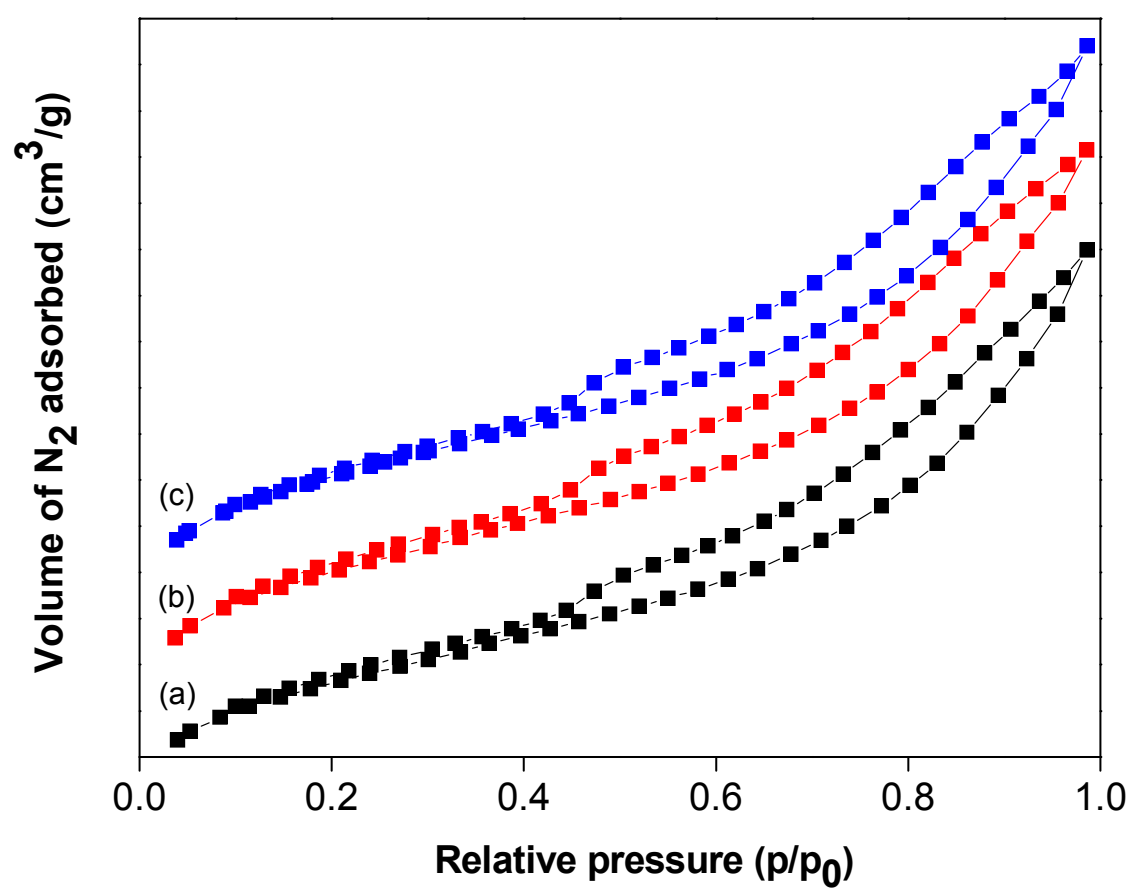

Figure 5. $\mathrm{N}_{2}$ sorption isotherms of AC (a), oxidized AC (b) and EDTA-AC (c).

Table 2. Area-volume data of AC, oxidized AC and EDTA-AC

\begin{tabular}{|c|c|c|c|}
\hline Adsorbent & $\begin{array}{l}\text { Specific surface } \\
\text { area }\left(\mathrm{m}^{2} \mathrm{~g}^{-1}\right)\end{array}$ & $\begin{array}{l}\text { Pore volume } \\
\left(\mathrm{cm}^{3} \mathrm{~g}^{-1}\right)\end{array}$ & $\begin{array}{l}\text { Pore diameter } \\
(\mathrm{nm})\end{array}$ \\
\hline Norit AC & 711 & 0.41 & 1.54 \\
\hline Oxidized AC & 761 & 0.40 & 1.54 \\
\hline
\end{tabular}




\subsection{TGA and CHN}

The presence of EDTA-groups on the surface of AC was determined by combining TGA and CHN analysis. The TGA traces of AC, oxidized AC and EDTA-AC are presented in Figure 6. No major mass loss was observed for the original AC sample up to $600{ }^{\circ} \mathrm{C}$. From that temperature on, partial charring might explain the mass loss of about $20 \%$. The oxidized AC shows already a mass decrease from $200{ }^{\circ} \mathrm{C}$ on because of the decomposition of surface oxygen groups, such as carboxylic, lactonic and phenolic groups. Compared to the original sample, the residual mass decreased with an additional $11 \%$ after oxidation. In EDTA-functionalized AC, the gradual mass loss is comparable with the oxidized sample up to $200{ }^{\circ} \mathrm{C}$, by decomposition of free carboxylic acid and hydroxyl groups. Above $400{ }^{\circ} \mathrm{C}$, a considerable, additional mass loss was observed due to the complete decomposition of the (amine and carboxylic acid) functional groups in EDTA. Above $700{ }^{\circ} \mathrm{C}$, the observed mass loss might be attributed to the condensation of the silanol $-\mathrm{OH}$ groups. The residual mass of EDTA-AC was $17 \%$ lower than that of oxidized AC, which is due to the presence of the chelating agent in EDTA-AC. A TGA analysis of the materials performed in air is presented in Figure S4. Here, AC and oxidized AC showed $1 \%$ of residual mass, but EDTA-functionalized AC showed $6 \%$ of residual mass. The difference is explained by the presence of inorganic silica in EDTAfunctionalized $\mathrm{AC}$, which does not thermally decompose. Combined with the results of a CHN elemental analysis, these observations showed the success of the functionalization procedure (Table 3). By comparison of the nitrogen mass percentages in oxidized AC 
and EDTA-AC (synthesized in isopropanol), the amount of functionalization could be calculated to be $128 \mathrm{mg} \mathrm{g}^{-1}$ of TMS-EDTA functionalized per gram of AC.

Table 3. Elemental analysis of AC materials synthesized by different methods

\begin{tabular}{ccccc}
\hline Adsorbent & $\mathbf{C \%}$ & $\mathbf{H} \%$ & $\mathbf{N \%}$ & $\mathbf{O} \%$ \\
\hline Norit ${ }^{\mathbb{B}}$ AC & 91.70 & 0.87 & 0.57 & 6.86 \\
Oxidized AC & 74.59 & 1.18 & 0.52 & 23.71 \\
EDTA-AC & & & & \\
(Methanol) & 70.34 & 1.56 & 0.98 & 27.12 \\
EDTA-AC & & & & \\
(Isopropanol) & 65.64 & 2.08 & 1.60 & 30.68 \\
EDTA-AC & & & & \\
(TEOS) & 45.34 & 2.21 & 1.73 & 50.72 \\
\hline
\end{tabular}




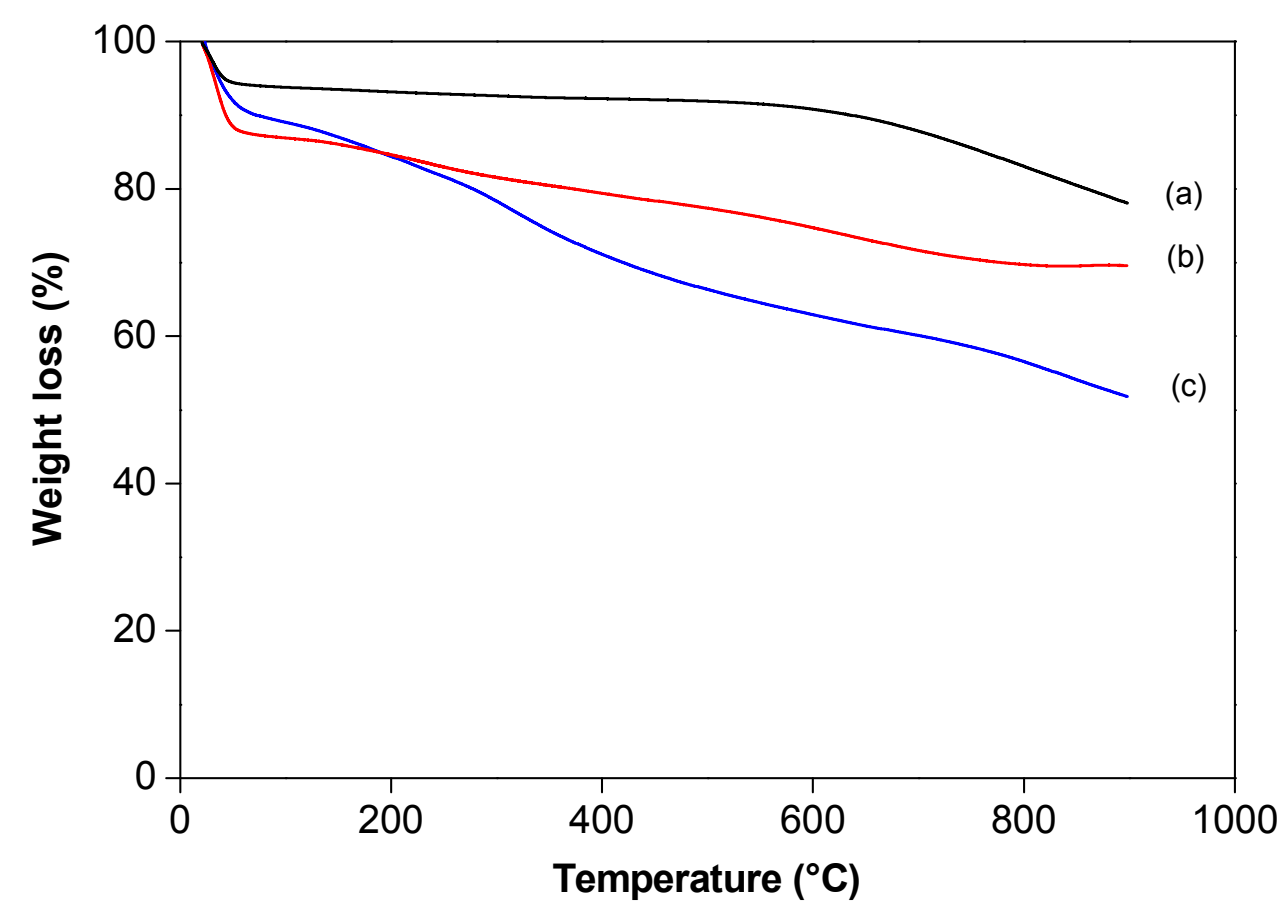

Figure 6. TGA traces of AC (a), oxidized AC (b) and EDTA-AC - prepared in isopropanol (c), all recorded under nitrogen atmosphere.

\subsection{Adsorption isotherm}

Variation of the $\mathrm{Nd}(\mathrm{III})$ concentration $\left(10\right.$ to $\left.300 \mathrm{mg} \mathrm{L}^{-1}\right)$ allowed to construct adsorption isotherms for AC, oxidized AC and EDTA-AC (Figure 7). Adsorption values were fitted with the Langmuir and Freundlich adsorption models. The linear expression of a Langmuir isotherm is given as follows (Equation 4): ${ }^{44}$

$$
\frac{C_{e}}{q_{e}}=\frac{1}{q_{\max } b}+\frac{C_{e}}{q_{\max }}
$$


where $q_{e}$ is the equilibrium adsorption amount $\left(\mathrm{mg} \mathrm{g}^{-1}\right), C_{e}$ the equilibrium concentration of $\mathrm{Nd}(\mathrm{III})\left(\mathrm{mg} \mathrm{L}^{-1}\right), q_{\max }$ the maximum adsorption capacity $\left(\mathrm{mg} \mathrm{L}^{-1}\right)$ and $b$ a constant related to the adsorption energy. The parameters $q_{\max }$ and $b$ can be derived from the slope and intercept of the plot of $C_{e}$ versus $C_{e} / q_{e}$ (Figure 8a). The linear expression of a Freundlich isotherm is expressed as follows (Equation 5): ${ }^{44}$

$$
\log q_{e}=\log K_{f}+\frac{1}{n} \log C_{e}
$$

where $q_{e}$ is the equilibrium adsorption amount $\left(\mathrm{mg} \mathrm{g}^{-1}\right), C_{e}$ the equilibrium concentration of $\mathrm{Nd}(\mathrm{III})\left(\mathrm{mg} \mathrm{L}^{-1}\right)$, and $K_{f}$ and $n$ Freundlich constants. The values of $K_{f}$ and $1 / n$ were determined from the slope and intercept of the plot of $\log q_{e}$ versus $\log C_{e}$ (Figure $8 \mathbf{b}$ ).

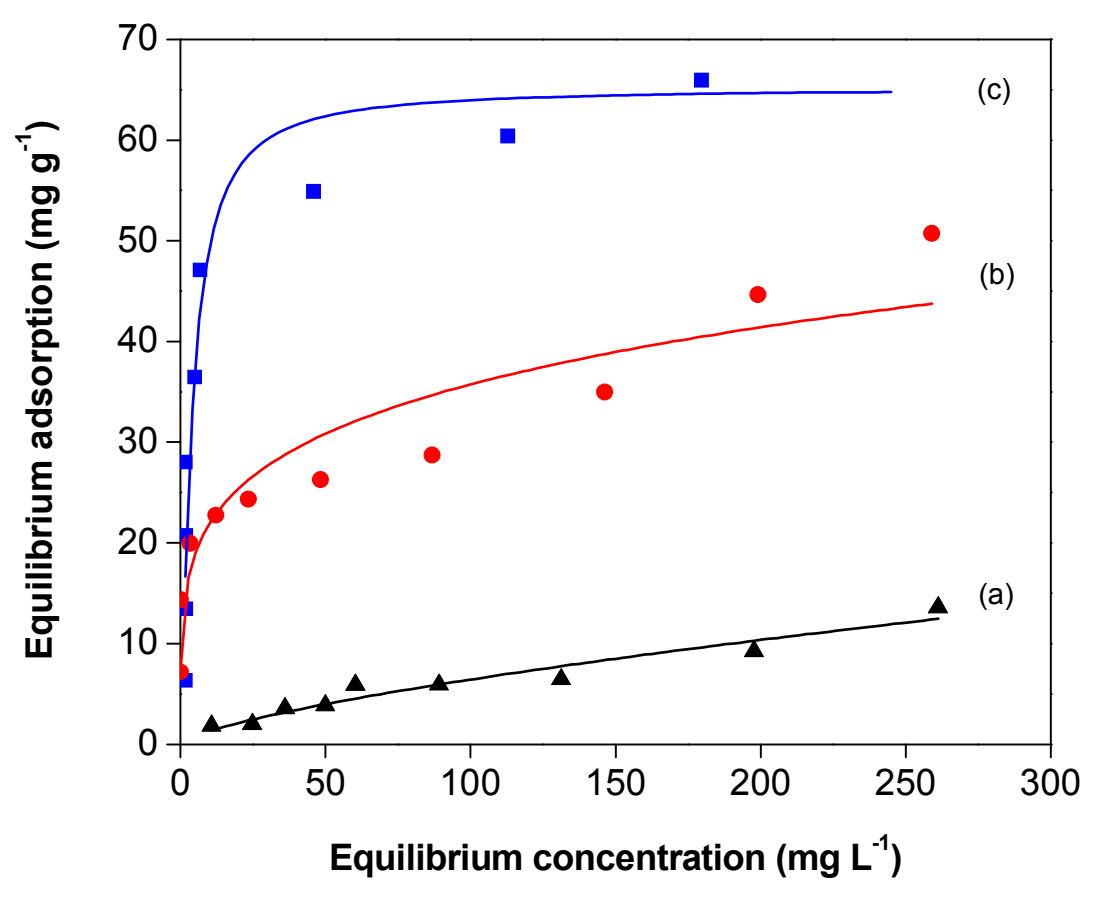


Figure 7. Equilibrium adsorption isotherms of Nd(III) on AC (a), oxidized-AC (b) and EDTA-AC (c), fitted by the Langmuir isotherm model.

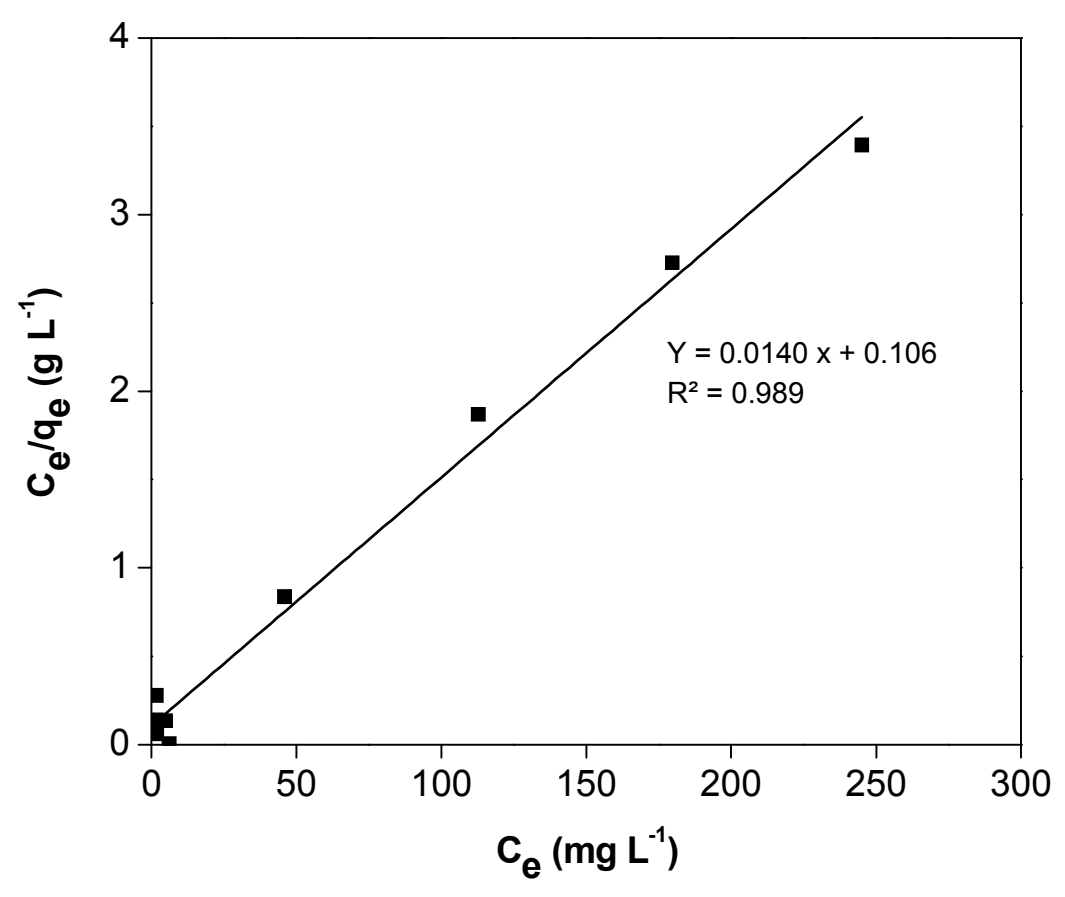

(a) 


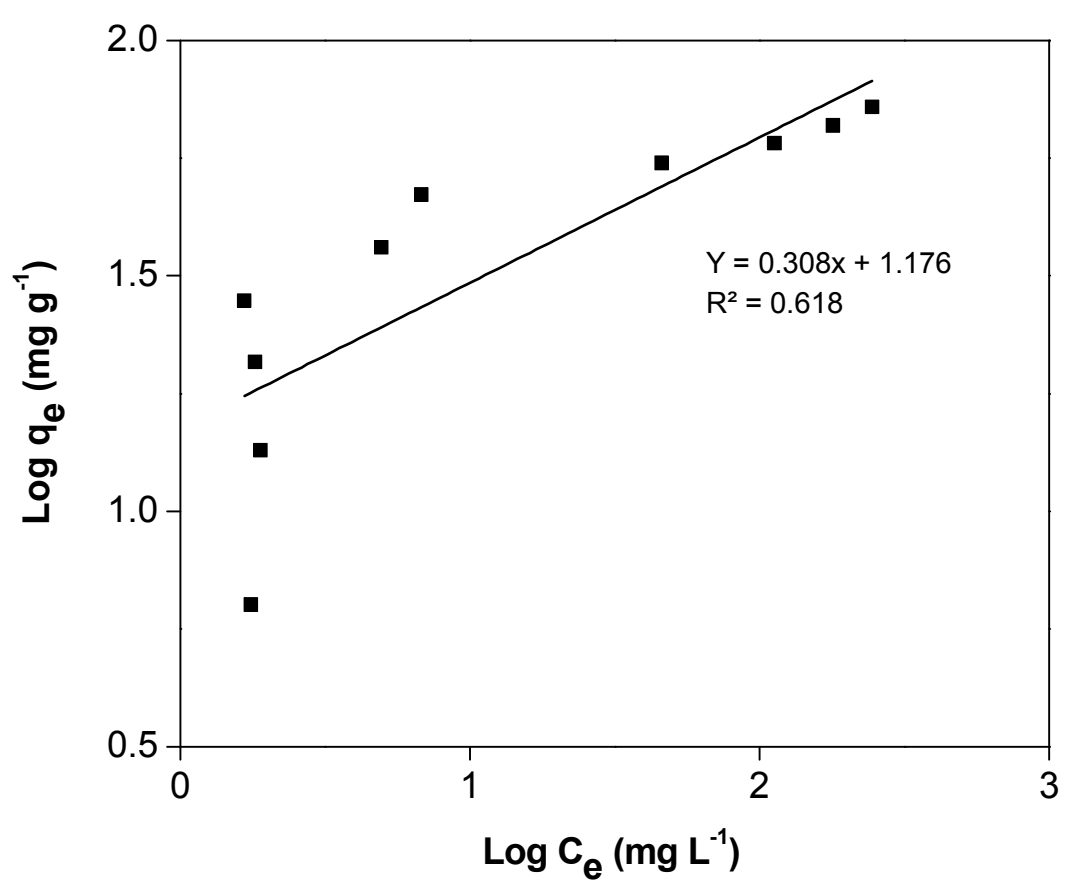

(b)

Figure 8. Linear Langmuir (a) and Freundlich (b) plots for Nd(III) adsorption on

\section{EDTA-AC.}

The obtained parameters of both Langmuir and Freundlich isotherm models are listed in Table S3. A Freundlich constant greater than 1 indicated that the adsorption of $\mathrm{Nd}(\mathrm{III})$ on EDTA-AC was an energetically favorable process. The $\mathrm{Nd}(\mathrm{III})$ adsorption isotherm data fitted best to the Langmuir model, for which a linear correlation coefficient of 0.989 was obtained. This indicates the presence of a monolayer of adsorbed $\mathrm{Nd}(\mathrm{III})$ ions on the surface of EDTA-AC. The maximum adsorption capacity of EDTA-AC was derived to be $71.42 \mathrm{mg} \mathrm{g}^{-1}$, whereas lower values were calculated for the nonfunctionalized samples, respectively $50.75 \mathrm{mg} \mathrm{g}^{-1}$ for the oxidized AC and only $19.08 \mathrm{mg}$ $\mathrm{g}^{-1}$ for the original AC. From these results, it is evident that (1) the immobilization of 
EDTA over AC significantly enhanced the adsorption capacity for $\mathrm{Nd}(\mathrm{III})$, and (2) since the observed adsorption capacity was higher than the theoretical value obtained from the amount of functionalization (55.60 $\mathrm{mg} \mathrm{Nd}(\mathrm{III})$ per gram of EDTA-AC), not only the incorporated TMS-EDTA chelating agent, but also the non-selective oxygen groups on the AC surface contribute to the overall adsorption process. From Table 4, where an overview of adsorption capacity values is given for different adsorbent systems, it appears that EDTA-AC is an adsorbent material with a high adsorption capacity.

Table 4. Comparison of different adsorbent materials regarding adsorption capacity values from aqueous $\mathrm{Nd}($ III) solutions

\begin{tabular}{|c|c|c|c|}
\hline \multirow[b]{2}{*}{ Adsorbent system } & \multicolumn{3}{|c|}{ Adsorption } \\
\hline & $\mathbf{p H}$ & $\begin{array}{l}\text { capacity } \\
\left(\mathrm{mg} \mathrm{g}^{-1}\right)\end{array}$ & Reference \\
\hline Native AC & 5.0 & 19.1 & present work \\
\hline EDTA-AC & 5.0 & 71.4 & present work \\
\hline EDTA-chitosan & 5.0 & 74.0 & {$[38]$} \\
\hline DTPA-chitosan-silica & 3.0 & 38.9 & {$[45]$} \\
\hline Alginate-TMOS & 3.1 & 53.4 & {$[46]$} \\
\hline $\begin{array}{l}\text { DETA-functionalized } \\
\text { chitosan nanoparticles }\end{array}$ & 5.0 & 54.8 & {$[47]$} \\
\hline
\end{tabular}



P-functionalized silica
3.0
73.6

[48]

\subsection{Adsorption kinetics}

The adsorption kinetics of $\mathrm{Nd}(\mathrm{III})$ adsorption by EDTA-AC at $\mathrm{pH} 5$ is shown in Figure 9. One can see that $\mathrm{Nd}(\mathrm{III})$ ions were completely removed from the aqueous solution by EDTA-AC within 15 min of contact time. The rapid adsorption of $\mathrm{Nd}(\mathrm{III})$ may be attributed to the textural properties of EDTA-AC. The large surface area of EDTA-AC $\left(741 \mathrm{~m}^{2} \mathrm{~g}^{-1}\right)$, combined with its high porosity, enables a high accessibility of the surface functional groups to accommodate the trivalent cation. Compared to similar EDTA-functionalized adsorbent systems, the fast kinetics are remarkable and favor the use of this low-cost adsorbent material for practical, bulk-scale applications.

The experimental data fitted well with the pseudo-second-order rate equation, with the $\mathrm{R}^{2}$ value close to 0.999 . The linear form of the pseudo-second-order rate equation is expressed by Equation 6. ${ }^{49}$

$$
\frac{t}{q_{t}}=\frac{1}{k_{2} q_{e}^{2}}+\frac{1}{q_{e} t}
$$

where $q_{e}$ and $q_{t}$ are the adsorption amount ( $\mathrm{mg} \mathrm{g}^{-1}$ ) at equilibrium and time $t$, respectively, and $k_{2}$ is the rate constant of pseudo-second-order adsorption $\left(\mathrm{g} \mathrm{mg}^{-1} \mathrm{~min}^{-1}\right)$. The $q_{e}$ (55.12 $\left.\mathrm{mg} \mathrm{g}^{-1}\right)$ and $k_{2}(0.042)$ values were obtained from the slope and intercept of the $t / q_{t}$ versus time plot, as shown in Figure 10. Since the adsorption process fits well with the pseudo-second-order kinetic model, chemisorption, i.e. the chemical reaction at the 
adsorbent surface, is implied to be the rate-limiting step. This means that the complexation reactions between EDTA and $\mathrm{Nd}(\mathrm{III})$ determine the overall rate constant of the process, rather than diffusion-related phenomena in the adsorbent material.

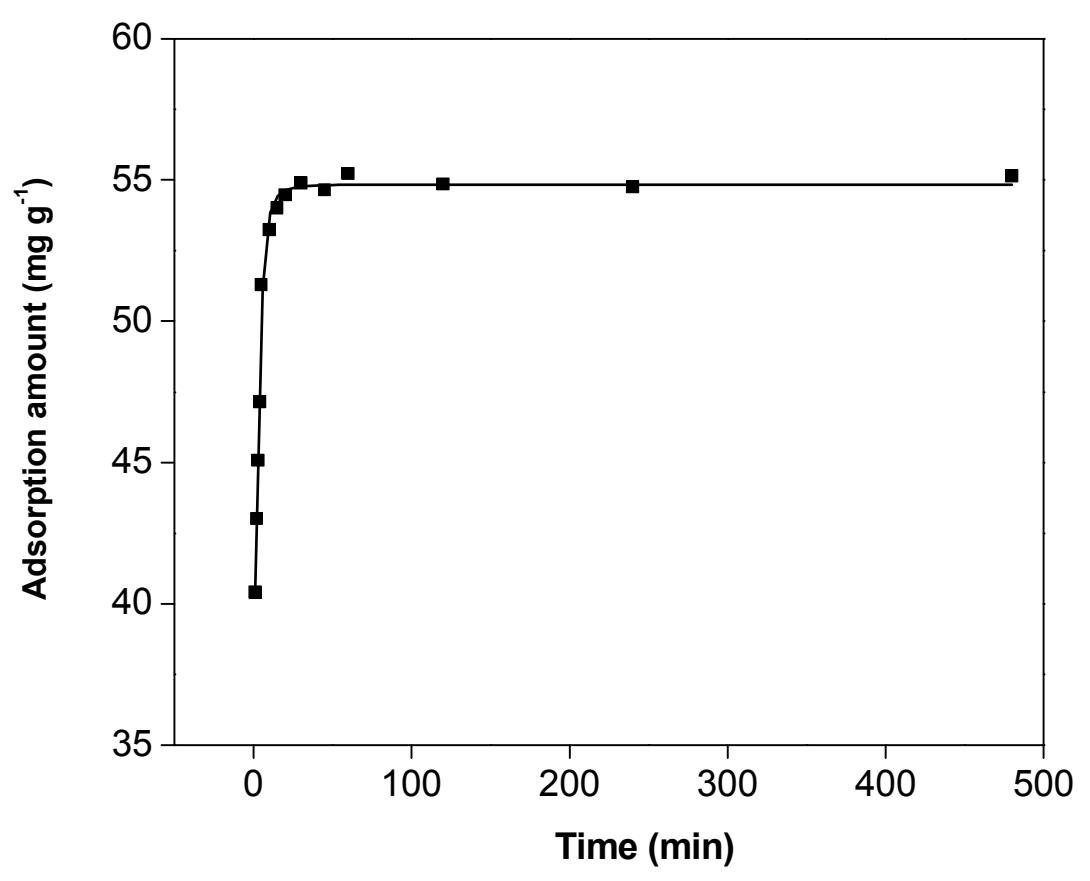

Figure 9. Adsorption kinetics of Nd(III) on EDTA-AC, fitted by the pseudo-secondorder kinetic adsorption model. 


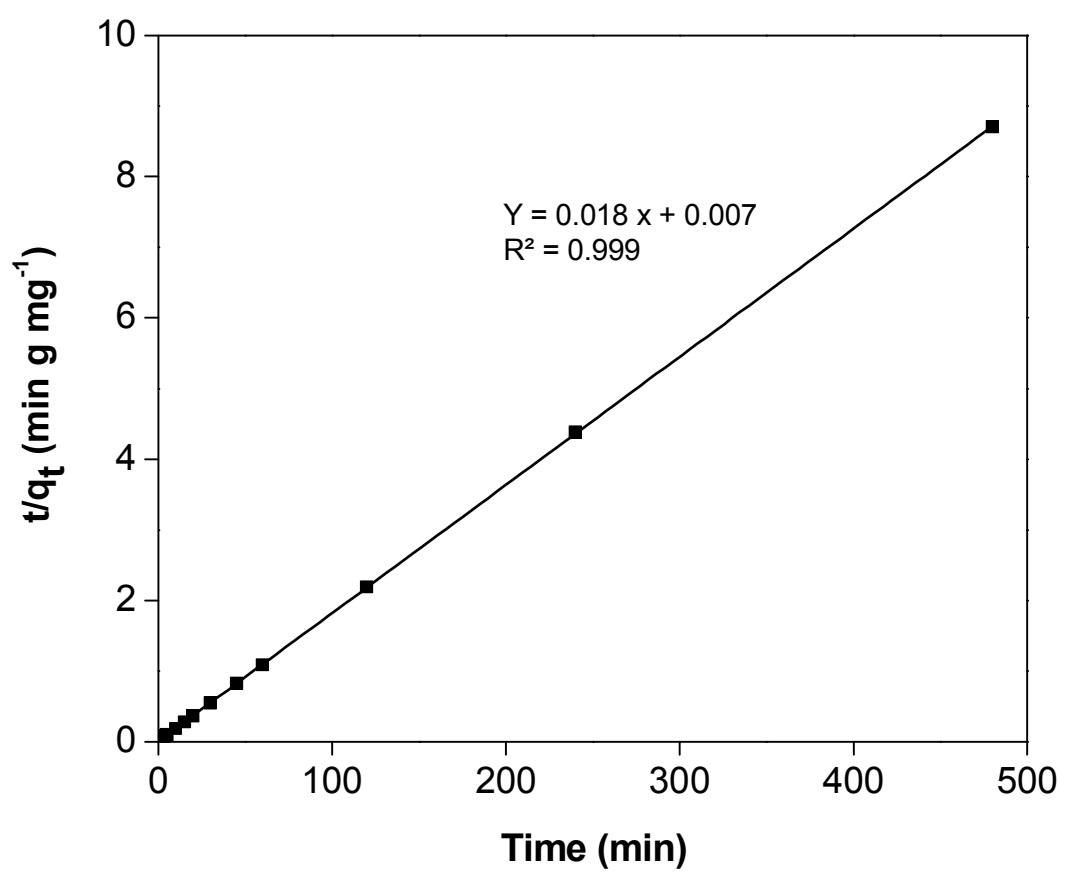

Figure 10. Pseudo-second-order kinetic plot for Nd(III) adsorption on EDTA-AC.

\subsection{Effect of $\mathrm{pH}$}

The $\mathrm{pH}$ of an aqueous solution has a remarkable influence on the efficiency of the metal-ion adsorption process as it controls (de)protonation of the functional groups on the surface of the adsorbent material. In the present study, the adsorption of $\mathrm{Nd}(\mathrm{III})$ on EDTA-AC was studied at (equilibrium) $\mathrm{pH}$ levels ranging from $\mathrm{pH} 1$ to 7 (Figure 11). Above $\mathrm{pH} 7, \mathrm{Nd}(\mathrm{III})$ ions undergo hydrolysis and precipitate as $\mathrm{Nd}(\mathrm{OH})_{3}$ because the ionic product $\left(\mathrm{Q}_{\mathrm{sp}}\right)$ exceeds the solubility product $\left(\mathrm{K}_{\mathrm{sp}}=10^{-23}\right)$ in solutions with a $\mathrm{Nd}(\mathrm{III})$ concentration higher than $0.01 \mathrm{M}$. As shown in the figure, the adsorption of $\mathrm{Nd}(\mathrm{III})$ increased sharply when increasing the $\mathrm{pH}$ value, until a maximal plateau value was obtained around $\mathrm{pH} 5$. 


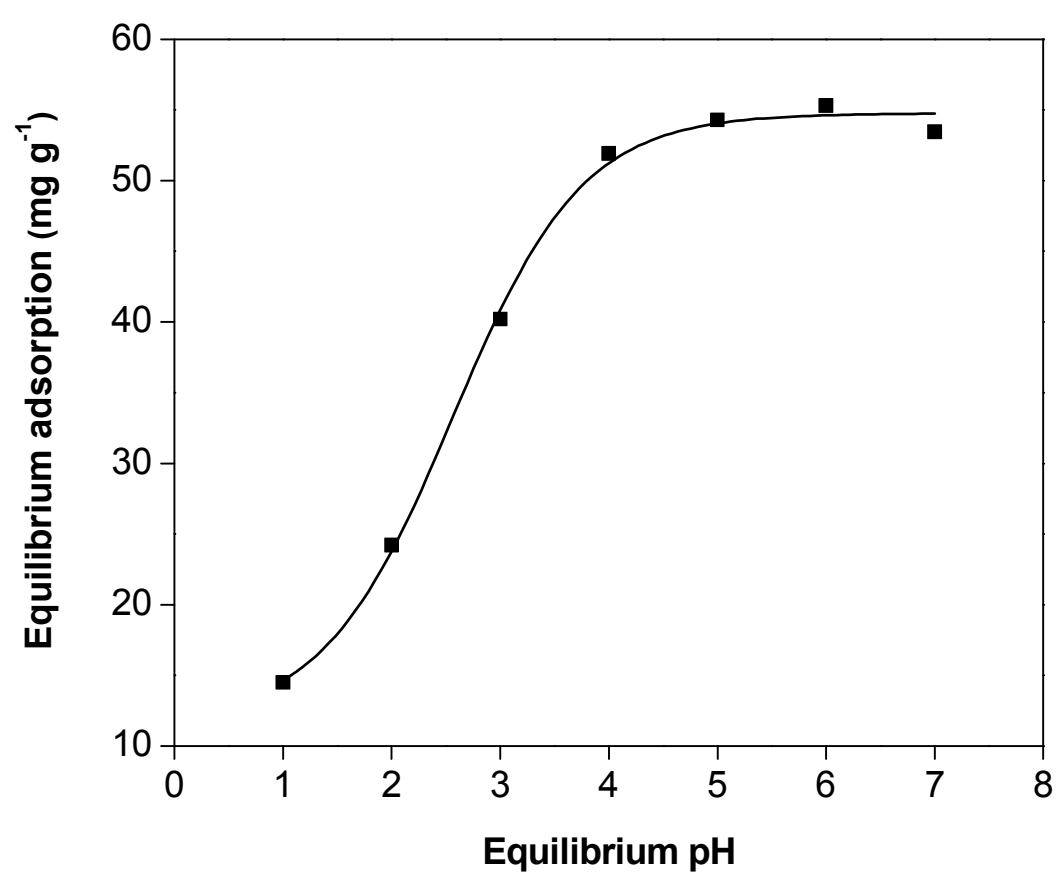

Figure 11. Effect of pH on Nd(III) removal using EDTA-AC.

\subsection{Thermodynamic studies}

The adsorption of $\mathrm{Nd}(\mathrm{III})$ on EDTA-AC at different temperatures was studied (Figure S5). Some of the thermodynamic functions like free energy $(\Delta G)$, entropy $(\Delta S)$ and enthalpy $(\Delta H)$ change were calculated to learn about the feasibility of the adsorption process. $\Delta G$ was calculated from the Gibbs free energy equation for a system at equilibrium (Equation 7), so $\Delta S$ and $\Delta H$ could be calculated from the Van 't Hoff equation (Equation 8). ${ }^{50}$

$$
\Delta G^{\circ}=-R T \ln K_{d}
$$




$$
\ln K_{d}=-\frac{\Delta H^{\circ}}{R T}+\frac{\Delta S^{\circ}}{R}
$$

where $\mathrm{T}(\mathrm{K})$ is the absolute temperature, $\mathrm{R}\left(8.314 \mathrm{~J} \mathrm{~mol}^{-1} \mathrm{~K}^{-1}\right)$ the gas constant and $K_{d}=$ $q_{e} / C_{e}\left(\mathrm{~L} \mathrm{~g}^{-1}\right)$ the equilibrium constant. $\Delta H^{\circ}$ and $\Delta S^{\circ}$ were calculated from the slope and the intercept of the plot of $\ln K_{d}$ vs. 1/T (Figure 12) and the values are listed in Table S4. The standard enthalpy value of the system was positive, so the adsorption is endothermic in nature. The standard entropy value was positive as well, indicating that significant changes occur in the internal structure of the adsorbent, favoring a high affinity for $\mathrm{Nd}(\mathrm{III})$. Consequently, the values of $\Delta G^{\circ}$ were negative for all temperatures, indicating that the adsorption of $\mathrm{Nd}(\mathrm{III})$ by EDTA-AC is a spontaneous process. From the stability constant between the chelating agent EDTA and $\mathrm{Nd}(\mathrm{III}), \log \mathrm{K}=16.61$, we could derive the corresponding Gibbs free energy at room temperature, equal to $-94.71 \mathrm{~kJ} / \mathrm{mol}$. Since the value for free EDTA is lower than the value obtained for EDTA-AC, this indicates that $\mathrm{Nd}(\mathrm{III})$ complexation by free EDTA is more favorable than adsorption with EDTAAC. However, given that the $\Delta G^{\circ}$ values decreased with increasing temperature, this implies that adsorption becomes more favorable at higher temperatures. This opens opportunities for industrial waste streams that come at a higher process temperature. 


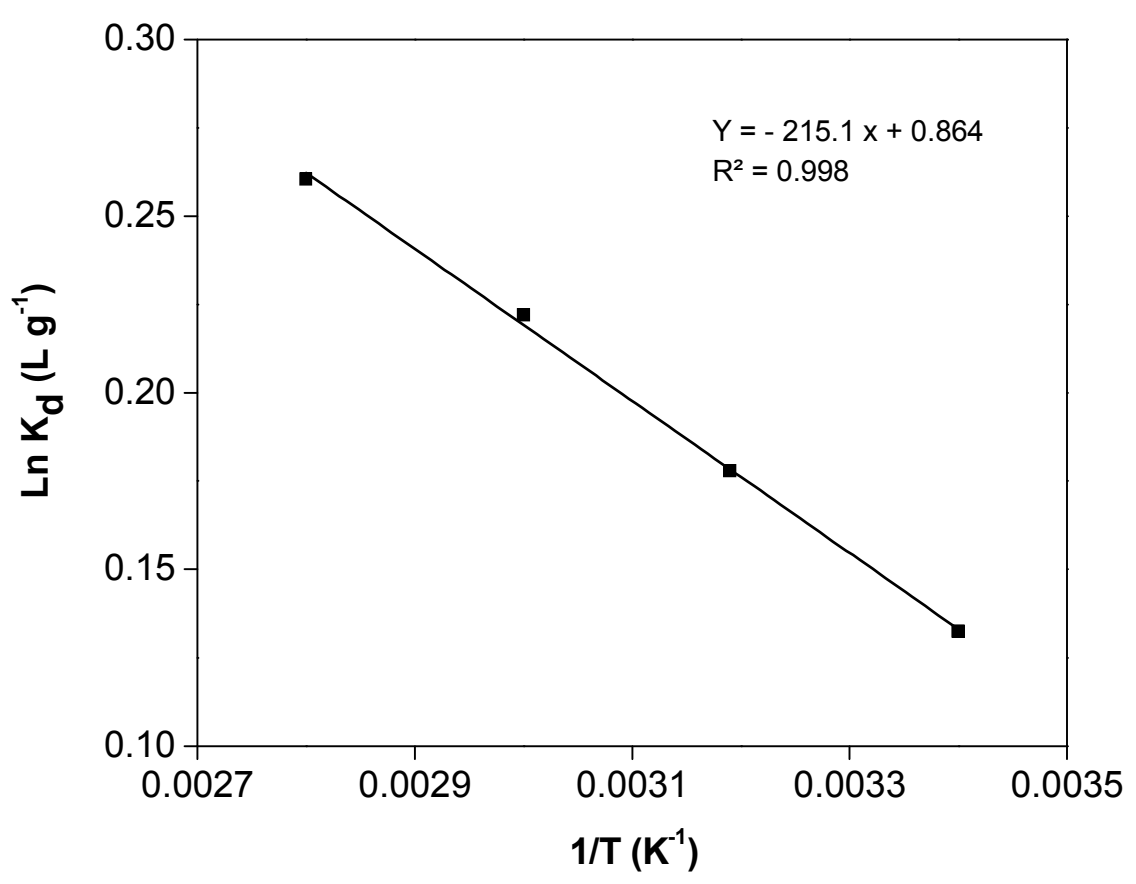

Figure 12. Van't Hoff plots for the adsorption of Nd(III) on EDTA-AC.

\subsection{Adsorption of rare earths from single- and binary-element solutions}

The adsorption of different rare-earth ions on EDTA-AC was studied (Figure 13).

High adsorption values were observed for all the lanthanide ions. Moreover, an increasing trend in adsorption was observed with increasing atomic mass. This might be attributed to the "lanthanide contraction". As a consequence of their higher charge density, the heavier lanthanide ions generally have a higher affinity for the coordinating entities in EDTA-AC compared to the lighter lanthanide ions. These differences in selectivity between different rare-earth ions may eventually be exploited to separate them from each other. 


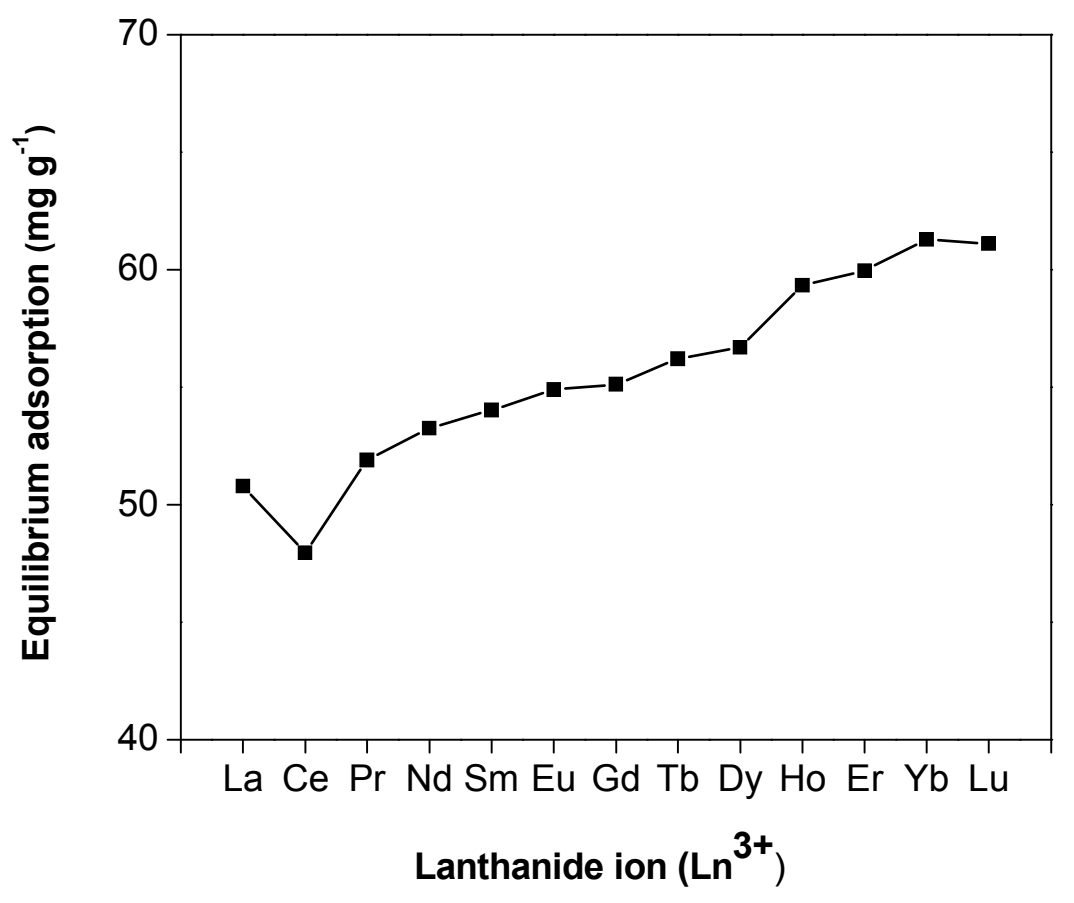

Figure 13. Equilibrium adsorption capacity of lanthanide ions from single-element solutions (metal ion concentration $=25 \mathrm{mg} \mathrm{L}^{-1}$ ) by EDTA-AC.

To elaborate on the selectivity of the EDTA-functionalized AC, adsorption tests were performed from binary mixtures of several metal ion pairs, $\mathrm{La}(\mathrm{III}) / \mathrm{Ni}(\mathrm{II})$, $\mathrm{Sm}(\mathrm{III}) / \mathrm{Co}(\mathrm{II}), \mathrm{Eu}(\mathrm{III}) / \mathrm{Y}(\mathrm{III})$ and $\mathrm{Dy}(\mathrm{III}) / \mathrm{Nd}(\mathrm{III})$, and the respective adsorption efficiencies compared (Figure 14). These particular metal pairs were chosen because of their occurrence in End-of-Life waste sources like batteries, magnets and lamp phosphors. ${ }^{5}$ The adsorption of La(III), Sm(III), Eu(III) and Dy(III) was found to be higher than that of respectively $\mathrm{Ni}(\mathrm{II}), \mathrm{Co}(\mathrm{II}), \mathrm{Y}(\mathrm{III})$ and $\mathrm{Nd}(\mathrm{III})$. From the considerable differences in uptake percentage (up to a difference of 70 to $17 \%$ for the $\mathrm{Sm}$ (III)/Co(II) pair), the separation capability of this low-cost EDTA-AC adsorbent material is evident. 


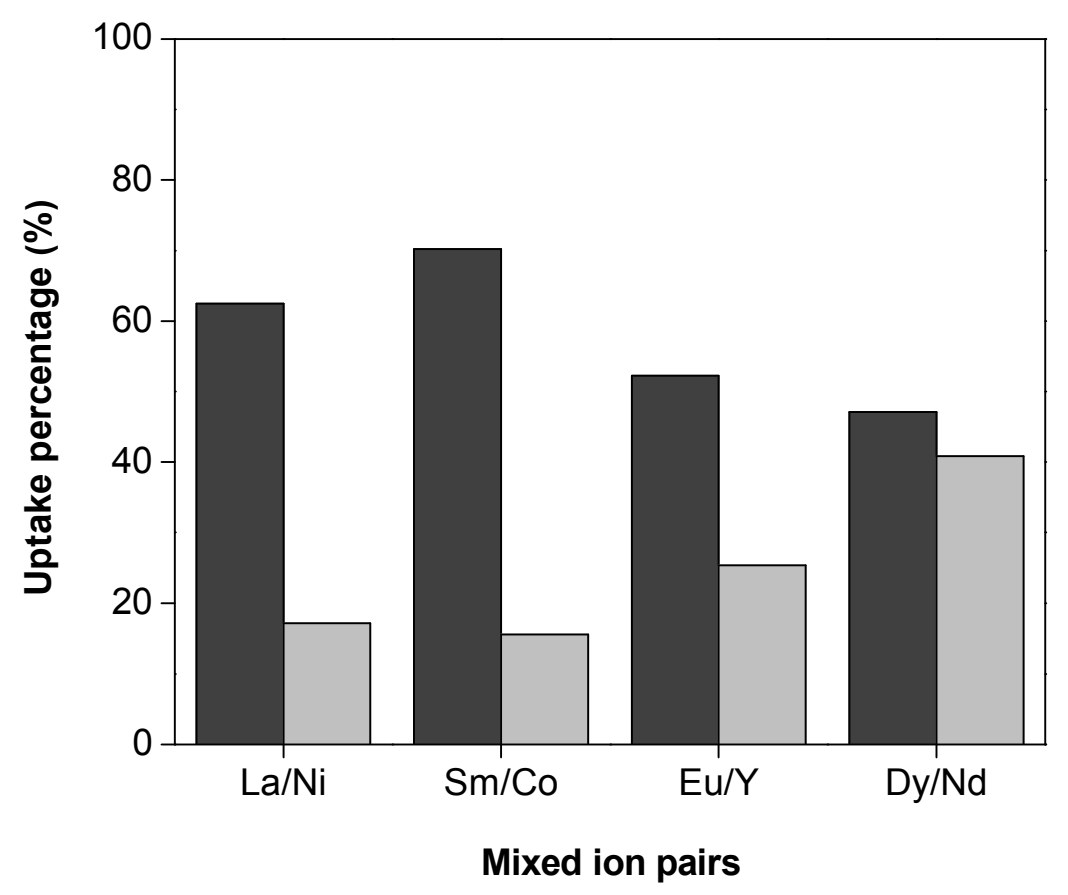

Figure 14. Selective uptake of metal ions from equimolar, binary mixtures (concentration of each metal ion $=1 \mathrm{mmol} \mathrm{L}^{-1}$ ) by EDTA-AC.

\subsection{Stripping and reusability}

Stripping (desorption) of immobilized metal ions is required for further processing of the recovered metal values and for the regeneration of the adsorbent material. Acidic solutions containing various concentrations of $\mathrm{HCl}$, ranging from 0.01 to $1 \mathrm{M}$, were mixed with $\mathrm{Nd}(\mathrm{III})$ loaded AC particles (Figure S6). An increase in the acid concentration resulted in an increased stripping efficiency, up to $99 \%$ stripping in only one stripping cycle with a $1 \mathrm{M} \mathrm{HCl}$ solution. Since reusability plays a vital role in bulkscale production processes, regeneration of the adsorbent was tested over five adsorption- 
desorption cycles, as shown in Figure 15. The adsorption capacity decreased by 5.3\% in the first regeneration cycle and showed a cumulative decrease in adsorption capacity of less than $4 \%$ in the subsequent four cycles. The regeneration efficiency was maintained up to $90 \%$ after the fifth regeneration cycle, revealing the potential of EDTA-AC for industrial applications.

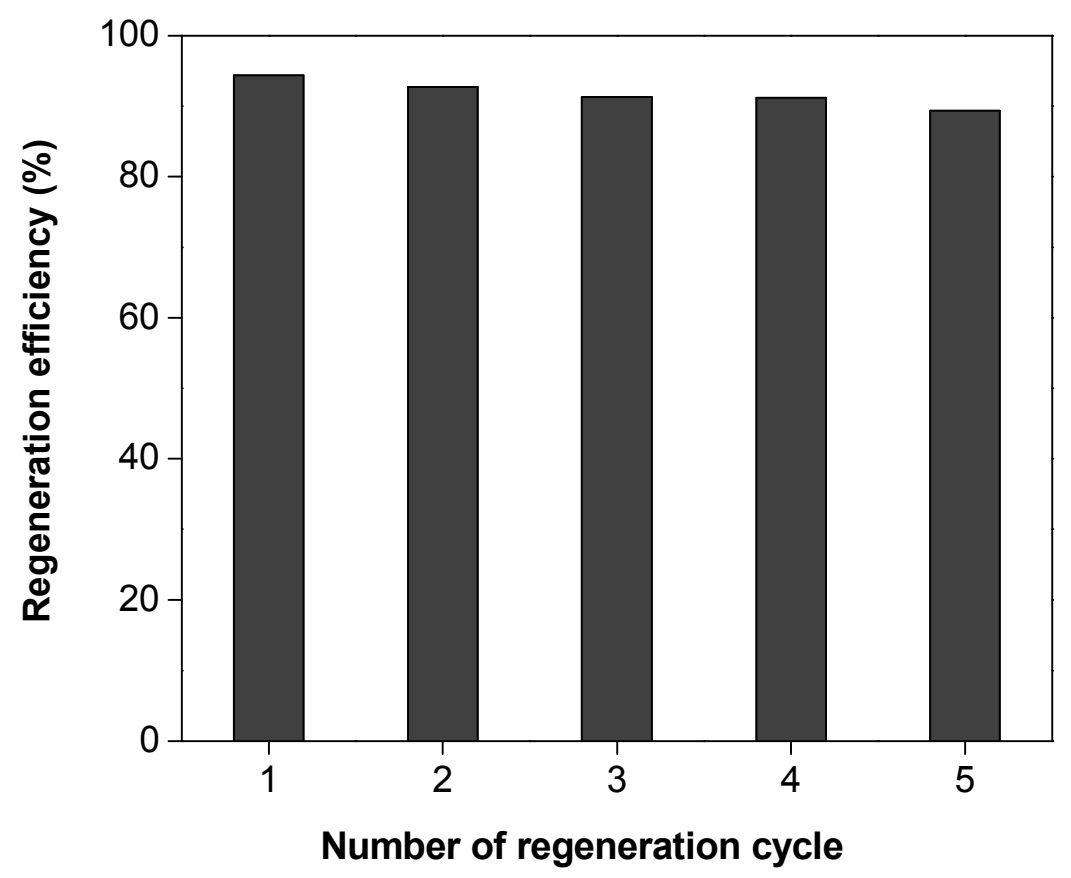

Figure 15. Regeneration efficiency of EDTA-AC for the uptake of Nd(III) over consecutive adsorption/desorption cycles. 


\section{CONCLUSIONS}

By immobilization of the chelating agent EDTA on AC, an adsorbent material with an excellent capability of recovering rare earths from aqueous solutions was obtained.

Characterization of the functionalized AC particles elucidated a high specific surface area $\left(740 \mathrm{~m}^{2} \mathrm{~g}^{-1}\right)$ and micropores with a volume of $0.41 \mathrm{~cm}^{3} \mathrm{~g}^{-1}$, enabling a high accessibility of the functional groups and avoiding any kind of diffusion problem. The amount of functionalization was determined to be $128 \mathrm{mg} \mathrm{g}^{-1}$. Adsorption was fast: equilibrium was reached within $15 \mathrm{~min}$. The adsorption capacity of EDTA-AC was found to be $71.42 \mathrm{mg} \mathrm{g}^{-1}$, which was almost 4 times higher than that of pure AC. Separations were studied for the binary mixtures $\mathrm{La}(\mathrm{III}) / \mathrm{Ni}(\mathrm{II}), \mathrm{Sm}(\mathrm{III}) / \mathrm{Co}(\mathrm{II}), \mathrm{Eu}(\mathrm{III}) / \mathrm{Y}(\mathrm{III})$ and Dy(III)/Nd(III), typically present in electronic waste. A high selectivity was achieved towards the (heavier) REEs. The regeneration efficiency remained higher than $90 \%$ after five consecutive adsorption-desorption cycles. Because the EDTA-functionalized AC is cheap, easily synthesized, chemically stable and highly efficient, we are convinced that it could find application in bulk quantities for the recovery of rare earths from industrial waste water streams. 


\begin{abstract}
ASSOCIATED CONTENT
The Supporting Information is available free of charge on the ACS Publications website (http://pubs.acs.org/) at DOI: 10.1021/acs.iecr.Xxxxxxx. The file contains additional FTIR spectra (oxidation of $\mathrm{AC}$ by various concentrations of $\mathrm{HNO}_{3}$, functionalization in different solvent ratios methanol/water, and the use of TEOS in isopropanol/water), Raman D and G band values, particle size values and TGA traces in oxygen atmosphere for AC, oxidized AC and EDTA-AC, Langmuir and Freundlich adsorption isotherm constants and thermodynamic parameters for $\mathrm{Nd}(\mathrm{III})$ adsorption on EDTA-AC, effect of temperature on $\mathrm{Nd}(\mathrm{III})$ uptake by EDTA-AC and efficiency of stripping from $\mathrm{Nd}(\mathrm{III})$ loaded EDTA-AC with $\mathrm{HCl}$ solutions of different concentration.
\end{abstract}

\title{
AUTHOR INFORMATION \\ Corresponding Author \\ E-mail: joris.roosen@kuleuven.be \\ Phone: +32 16328204
}

\section{ORCID}

Cadiam Mohan Babu: 0000-0002-0052-052X

Koen Binnemans: 0000-0003-4768-3606

Joris Roosen: 0000-0002-9560-8283

\section{Author Contributions}


The manuscript was written through contributions of all authors. All authors have given approval to the final version of the manuscript.

\section{Notes}

The authors declare no competing financial interest.

\section{ACKNOWLEDGEMENTS}

The support by the Strategic Initiative Materials (SIM) in Flanders, within the MaRes program (under grant agreement $\mathrm{n}^{\circ} 150626$, “Get-A-Met" project), is acknowledged. The authors also wish to thank Dirk Henot, who performed the CHN analyses. 


\section{REFERENCES}

1. Zheng, X.; Wang, C.; Dai, J.; Shi W.; Yan, Y. Design of mesoporous silica hybrid materials as sorbents for the selective recovery of rare earth metals. J. Mater.

Chem. A. 2015, 3, 10327-10335.

2. Liu, E.; Zheng, X.; Xu, X.; Zhang, F.; Liu, E.; Wang, Y.; Li, C.; Yan, Y. Preparation of diethylenetriamine-modified magnetic chitosan nanoparticles for adsorption of rare-earth metal ions. New J. Chem. 2017, 41, 7739-7750.

3. Migaszewski, Z. M.; Gałuszka, A. The Characteristics, Occurrence, and Geochemical Behavior of Rare Earth Elements in the Environment: A Review. Crit. Rev. Environ. Sci. Technol. 2015, 45, 429-471.

4. Wang, L.; He, J.; Xia, A.; Cheng, M.; Yang, Q.; Du, C.; Wei, H.; Huang, X.; Zhou, Q. Toxic effects of environmental rare earth elements on delayed outward potassium channels and their mechanisms from a microscopic perspective. Chemosphere, 2017, 181, 690-698.

5. Binnemans, K.; Jones, P. T.; Blanpain, B.; Gerven, T. V.; Yang, Y.; Walton, A.; Buchert, M. Recycling of rare earths: a critical review. J. Clean. Prod. 2013, 51, $1-22$.

6. Zhu, Y.; Zheng Y.; Wang, A. A simple approach to fabricate granular adsorbent for adsorption of rare elements. Int. J. Biol. Macromolec. 2015, 72, 410-420.

7. Anastopoulos, I.; Bhatnagar, A.; Lima, E. C. Adsorption of rare earth metals: A review of recent literature. J. Mol. Liq. 2016, 221, 954-962. 
8. Kraemer, S. M.; Xu, J.; Raymond, K. N.; Sposito, G. Adsorption of Pb(II) and Eu(III) by Oxide Minerals in the Presence of Natural and Synthetic Hydroxamate Siderophores. Environ. Sci. Technol. 2002, 36, 1287-1291.

9. Shih, J. S.; Tsay, L. M.; Wu, S. C. Adsorption of Rare Earths with Crown Ether Adsorbents. Analyst. 1985, 110, 1387-1390.

10. Zhao, Z.; Sun, X.; Dong, Y.; Wang, Y. Synergistic Effect of Acid-Base Coupling Bifunctional Ionic Liquids in Impregnated Resin for Rare Earth Adsorption. ACS Sustainable Chem. Eng. 2016, 4, 616-624.

11. Ramasamy, D. L.; Wojtus, A.; Repo, E.; Kalliola, S.; Srivastava, V.; Sillanpaa, M. Ligand immobilized novel hybrid adsorbents for rare earth elements (REE) removal from waste water: Assessing the feasibility of using APTES functionalized silica in the hybridization process with chitosan. Chem. Eng. J. $2017,330,1370-1379$.

12. Ramasamy, D. L.; Repo, E.; Srivastava, V.; Sillanpaa, M.; Chemically immobilized and physically adsorbed PAN/acetylacetone modified mesoporous silica for the recovery of rare earth elements from the waste water-comparative and optimization study. Water Res. 2017, 114, 264-276.

13. Chen, W.; Wang, L.; Zhuo, M.; Wang, Y.; Fu, S.; Li, Y. Reusable colloidal graphene oxide suspensions combined with dialysis bags for recovery of trace Y(III) from aqueous solutions. RSC Adv. 2014, 4, 58778-58787.

14. Li, K.; Gao, Q.; Yadavalli, G.; Shen, X.; Lei, H.; Han, B.; Xia, K.; Zhou, C. Selective Adsorption of $\mathrm{Gd}^{3+}$ on a Magnetically Retrievable Imprinted 
Chitosan/Carbon Nanotube Composite with High Capacity. ACS Appl. Mater. Interfaces. 2015, 7, 21047-21055.

15. Moreno-Castilla, C.; Lopez-Ramon, M. V.; Carrasco-Marin, F. Changes in surface chemistry of activated carbons by wet oxidation. Carbon. 2000, 38, 19952001.

16. Figueiredo, J. L.; Pereira, M. F. R.; Freitas, M. M. A.; Orfao, J. J. M. Modification of the surface chemistry of activated carbons. Carbon. 1999, 37, 1379-1389.

17. Guerrero-Péreza, M. O.; Valero-Romero, M. J.; Hernández, S.; López Nieto, J. M.; Rodríguez-Mirasol, J. Lignocellulosic-derived mesoporous materials: An answer to manufacturing non-expensive catalysts useful for the biorefinery processes. Catal. Today. 2012, 195, 155-161.

18. Rosas, J. M.; Bedia, J.; Rodríguez-Mirasol, J.; Cordero, T. On the preparation and characterization of chars and activated carbons from orange skin. Fuel Process. Technol. 2010, 91, 1345-1354.

19. Shafeeyan, M. S.; Daud, W. M. A. W.; Houshmand, A.; Shamiri, A. A review on surface modification of activated carbon for carbon dioxide adsorption. J. Anal. Appl. Pyrolysis. 2010, 89, 143-151.

20. Shafeeyan, M. S.; Daud, W. M. A. W.; Houshmand, A.; Arami-Niya, A. Ammonia modification of activated carbon to enhance carbon dioxide adsorption: Effect of pre-oxidation. Appl. Surf. Sci. 2011, 257, 3936-3942. 
21. Diyuk, V. E.; Mariychuk, R. T.; Lisnyak, V. V.; Functionalization of activated carbon surface with sulfonated styrene as a facile route for solid acids preparation. Mater. Chem. Phys. 2016, 184, 138-145.

22. Starvin, A. M.; Rao, T. P. Solid phase extractive preconcentration of uranium(VI) onto diarylazobisphenol modified activated carbon. Talanta. 2004, 63, 225-232.

23. Yin, C. Y.; Aroua, M. K.; Daud, W. M. A. W. Review of modifications of activated carbon for enhancing contaminant uptakes from aqueous solutions. Sep. Purif. Technol. 2007, 52, 403-415.

24. Xin, X.; Wei, Q.; Yang, J.; Yan, L.; Feng, R.; Chen, G.; Du, B.; Li, H. Highly efficient removal of heavy metal ions by amine-functionalized mesoporous $\mathrm{Fe}_{3} \mathrm{O}_{4}$ nanoparticles. Chem. Eng. J. 2012, 184, 132-140.

25. Wang, J.; Zheng, S.; Shao, Y.; Liu, J.; Xu, Z.; Zhu, D. Amino-functionalized $\mathrm{Fe}_{3} \mathrm{O}_{4} @ \mathrm{SiO}_{2}$ core-shell magnetic nanomaterial as a novel adsorbent for aqueous heavy metals removal. J. Colloid Interface Sci. 2010, 349, 293-299.

26. Pan, S.; Zhang, Y.; Shen, H.; Hu, M. An intensive study on the magnetic effect of mercapto-functionalized nano-magnetic $\mathrm{Fe}_{3} \mathrm{O}_{4}$ polymers and their adsorption mechanism for the removal of $\mathrm{Hg}$ (II) from aqueous solution. Chem. Eng. J. 2012, $210,564-574$.

27. Anirudhan, T. S.; Jalajamony, S. Cellulose-based anion exchanger with tertiary amine functionality for the extraction of $\operatorname{arsenic}(\mathrm{V})$ from aqueous media. J. Environ. Manage. 2010, 91, 2201-2207.

28. Tavares, D. S.; Daniel-da-Silva, A. L.; Lopes, C. B.; Silva, N. J. O.; Amaral, V. S.; Rocha, J.; Pereira, E.; Trindade, T. Efficient sorbents based on magnetite 
coated with siliceous hybrid shells for removal of mercury ions. J. Mater. Chem. A, 2013, 1, 8134-8143.

29. Cui, L.; Wang, Y.; Gao, L.; Hu, L.; Yan, L.; Wei, Q.; Du, B. EDTA functionalized magnetic graphene oxide for removal of $\mathrm{Pb}(\mathrm{II}), \mathrm{Hg}$ (II) and $\mathrm{Cu}$ (II) in water treatment: Adsorption mechanism and separation property. Chem. Eng. J. 2015, 281, 1-10.

30. Madadrang, C. J.; Kim, H. Y.; Gao, G.; Wang, N.; Zhu, J.; Feng, H.; Gorring, M.; Kasner, M. L.; Hou, S. Adsorption Behavior of EDTA-Graphene Oxide for Pb (II) Removal. ACS Appl. Mater. Interfaces, 2012, 4, 1186-1193.

31. Repo, E.; Koivula, R.; Harjula, R.; Sillanpaa, M. Effect of EDTA and some other interfering species on the adsorption of Co(II) by EDTA-modified chitosan. Desalination, 2013, 321, 93-102.

32. Liu, Y.; Chen, M.; Hao, Y. Study on the adsorption of $\mathrm{Cu}(\mathrm{II})$ by EDTA functionalized $\mathrm{Fe}_{3} \mathrm{O}_{4}$ magnetic nano-particles. Chem. Eng. J. 2013, 218, 46-54.

33. Iqbal, S.; Yun, J. EDTA-functionalized mesoporous silica for the removal of corrosion products: Adsorption studies and performance evaluation under gamma irradiation. Microporous and Mesoporous Mater. 2017, 248, 149-157.

34. Sha, H.; Wu, Y.; Fan, Y.; Fang, P. The synthesis of Fe-Al hydroxides coated with EDTA-Cross-linked $\beta$-Cyclodextrin and adsorption mechanism for As (III). J. Mol. Liq. 2017, 242, 520-530.

35. Zhao, F.; Repo, E.; Meng, Y.; Wang, X.; Yin, D.; Sillanpaa, M. An EDTA- $\beta$ cyclodextrin material for the adsorption of rare earth elements and its application 
in preconcentration of rare earth elements in seawater. J. Colloid Interface Sci. $2016,465,215-224$.

36. Zhao, D.; Zhang, Q.; Xuan, H.; Chen, Y.; Zhang, K.; Feng, S.; Alsaedi, A.; Hayat T.; Chen, C. EDTA functionalized $\mathrm{Fe}_{3} \mathrm{O}_{4} /$ graphene oxide for efficient removal of U(VI) from aqueous solutions. J. Colloid Interface Sci. 2017, 506, 300-307.

37. Dupont, D.; Brullot, W.; Bloemen, M.; Verbiest, T.; Binnemans, K. Selective Uptake of Rare Earths from Aqueous Solutions by EDTA Functionalized Magnetic and Nonmagnetic Nanoparticles. ACS Appl. Mater. Interfaces. 2014, 6, 4980-4988.

38. Roosen, J.; Binnemans, K. Adsorption and chromatographic separation of rare earths with EDTA and DTPA functionalized chitosan biopolymers. J. Mater. Chem. A. 2014, 2, 1530-1540.

39. Goertzen, S. L.; Kim, D.; Oickle, T. A. M.; Tarasuk, A. C.; Andreas, H. A. Standardization of the Boehm titration. Part I. $\mathrm{CO}_{2}$ expulsion and endpoint determination. Carbon. 2010, 48, 1252-1261.

40. Dupont, D.; Luyten, J.; Bloemen, M.; Verbiest, T.; Binnemans, K. Acid-Stable Magnetic Core-Shell Nanoparticles for the Separation of Rare Earths. Ind. Eng. Chem. Res. 2014, 53, 15222-15229.

41. Liu, C.; Koyyalamudi, B. B.; Li, L.; Emani, S.; Wang, C.; Shaw, L. L. Improved capacitive energy storage via surface functionalization of activated carbon as cathodes for lithium ion capacitors. Carbon, 2016, 109, 163-172.

42. Wang, P.; Wang, J.; Wang, X.; Yu, H.; Yu, J.; Lei, M.; Wang, Y. One-step synthesis of easy-recycling $\mathrm{TiO}_{2}-\mathrm{rGO}$ nanocomposite photocatalysts with 
enhanced photocatalytic activity. Appl. Catal. B: Environ. 2013, 132-133, 452459.

43. Hidalgo, J. J. T.; Rosas, J. M.; Palomo, J.; Valero-Romero, M. J.; RodríguezMirasol, J.; Cordero, T.; Functionalization of activated carbons by $\mathrm{HNO}_{3}$ treatment: Influence of phosphorus surface groups. Carbon. 2016, 101, 409-419.

44. Gupta, K.; Biswas, K.; Ghosh, U. C. Nanostructure Iron(III)-Zirconium(IV) Binary Mixed Oxide: Synthesis, Characterization, and Physicochemical Aspects of Arsenic(III) Sorption from the Aqueous Solution. Ind. Eng. Chem. Res. 2008, 47, 9903-9912.

45. Roosen, J.; Spooren J.; Binnemans, K. Adsorption performance of functionalized chitosan-silica hybrid materials toward rare earths. J. Mater. Chem. A. 2014, 2, 19415-19426.

46. Roosen, J.; Pype, J.; Binnemans, K.; Mullens, S. Shaping of Alginate-Silica Hybrid Materials into Microspheres through Vibrating-Nozzle Technology and Their Use for the Recovery of Neodymium from Aqueous Solutions. Ind. Eng. Chem. Res. 2015, 54, 12836-12846.

47. Galhoum, A. A.; Mahfouz, M. G.; Abdel-Rehem, S. T.; Gomaa, N. A.; Atia, A. A.; Vincent, T.; Guibal, E. Diethylenetriamine-functionalized chitosan magnetic nano-based particles for the sorption of rare earth metal ions [ $\mathrm{Nd}(\mathrm{III}), \mathrm{Dy}(\mathrm{III})$ and Yb(III)]. Cellulose 2015, 22, 2589-2605.

48. Park, H.-J.; Tavlarides, L. L. Adsorption of Neodymium(III) from Aqueous Solutions Using a Phosphorus Functionalized Adsorbent. Ind. Eng. Chem. Res. $2010,49,12567-12575$. 
49. Ho, Y. S. Review of second-order models for adsorption systems. J. Hazard. Mater. 2006, 136, 681-689.

50. Ren, Y.; Abbood, H. A.; He, F.; Peng, H.; Huang, K. Magnetic EDTA-modified chitosan $/ \mathrm{SiO}_{2} / \mathrm{Fe}_{3} \mathrm{O}_{4}$ adsorbent: Preparation, characterization, and application in heavy metal adsorption Chem. Eng. J. 2013, 226, 300-311.

51. Seitz, M., Allen, G. O., Raymond, K. N. The Lanthanide Contraction Revisited. J. Am. Chem. Soc. 2007, 129, 11153-11160. 


\section{GRAPHICAL ABSTRACT:}

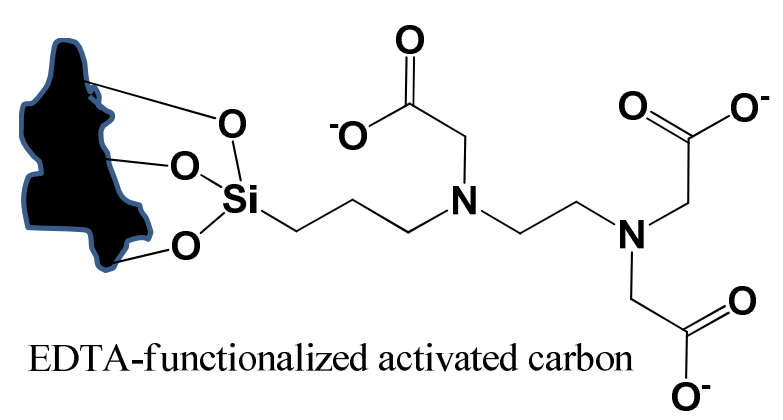

